\title{
REDD2-mediated inhibition of mTOR promotes dendrite retraction induced by axonal injury
}

\author{
B Morquette ${ }^{1,2,3}$, P Morquette ${ }^{1,3}$, J Agostinone ${ }^{1,2,3}$, E Feinstein $^{4}$, RA McKinney ${ }^{5}$, A Kolta ${ }^{1,3,6}$ and A Di Polo ${ }^{\star, 1,2,3}$
}

Dendritic defects occur in neurodegenerative diseases accompanied by axonopathy, yet the mechanisms that regulate these pathologic changes are poorly understood. Using Thy1-YFPH mice subjected to optic nerve axotomy, we demonstrate early retraction of retinal ganglion cell (RGC) dendrites and selective loss of mammalian target of rapamycin (mTOR) activity, which precede soma loss. Axonal injury triggered rapid upregulation of the stress-induced protein REDD2 (regulated in development and DNA damage response 2), a potent inhibitor of mTOR. Short interfering RNA-mediated REDD2 knockdown restored mTOR activity and rescued dendritic length, area and branch complexity in a rapamycin-dependent manner. Whole-cell recordings demonstrated that REDD2 depletion leading to mTOR activation in RGCs restored their light response properties. Lastly, we show that REDD2dependent mTOR activity extended RGC survival following axonal damage. These results indicate that injury-induced stress leads to REDD2 upregulation, mTOR inhibition and dendrite pathology causing neuronal dysfunction and subsequent cell death.

Cell Death and Differentiation (2015) 22, 612-625; doi:10.1038/cdd.2014.149; published online 26 September 2014

During normal neural development there is selective elimination of dendritic and axonal branches without loss of the neuron itself. ${ }^{1}$ This developmental pruning refines neuronal processes and ensures precise connectivity. Most of our current knowledge about structural changes in dendrites stems from studies of dendritic remodeling during development. ${ }^{2,3}$ In contrast, little is known about how dendritic arbors are affected by trauma or disease in the adult central nervous system (CNS). Defects in dendritic arborization and connectivity are being recognized as one of the first stages of neurodegeneration. Indeed, dendritic abnormalities and loss of synapses have been reported in neuropsychiatric disorders such as schizophrenia and depression, as well as in neurodegenerative conditions including Alzheimer's disease, stroke and glaucoma. ${ }^{4,5}$ Despite the fact that dendritic defects are likely to have devastating consequences on neuronal function and survival, the mechanisms that regulate dendrite degeneration in mature CNS neurons are poorly understood.

Recent studies have identified the mammalian target of rapamycin (mTOR) as a critical component of dendritic tree development. ${ }^{6-9}$ A substantial reduction in the number of dendritic branches and arbor shrinkage were observed in developing hippocampal neurons when mTOR was inhibited. $^{6,7}$ In addition, mTOR has been recently implicated in the regulation of dendritic spine morphology, synaptogenesis and synaptic plasticity. ${ }^{10,11}$ The emerging developmental role of mTOR in the regulation of dendritic dynamics prompted us to put forward the hypothesis that dysregulation of mTOR function might contribute to dendritic pathology in adult neurons following injury.

Many of the signals that impinge upon mTOR activity act through the tuberous sclerosis complex (TSC1/2), a negative regulator of mTOR function. For instance, stress signals such as hypoxia and energy depletion activate TSC1/2 through the REDD (regulated in development and DNA damage response) proteins, ${ }^{12-14}$ leading to the loss of mTOR activity. REDD2, a member of this family also known as DDIT4L or RTP801L, is an attractive target because in addition to being a potent mTOR inhibitor, it is implicated in stress responses leading to cell death. ${ }^{15,16}$ Although REDD2 is enriched in skeletal muscle and has been shown to inhibit mTOR signaling in response to leucine and stretch, ${ }^{17}$ its expression and function in the nervous system is currently unknown.

We used a model of acute optic nerve lesion in vivo to ask whether axonal damage had a direct effect on retinal ganglion cell (RGC) dendrite morphology and, if so, to identify the molecular mechanisms that regulate this injury-induced response. Our data demonstrate that axonal damage leads to substantial retraction of RGC dendritic arbors before soma loss. Optic nerve lesion led to selective REDD2 upregulation in RGCs, which coincided with the loss of mTOR activity. Short interfering RNA (siRNA)-mediated knockdown of REDD2

${ }^{1}$ Department of Neuroscience, CHUM Research Center, University of Montreal, Montreal, QC, Canada; ${ }^{2}$ University of Montreal Hospital Research Center (CR-CHUM), Montreal, QC, Canada; ${ }^{3}$ Groupe de Recherche sur le Système Nerveux Central (GRSNC), University of Montreal, Montreal, QC, Canada; ${ }^{4}$ Quark Pharmaceuticals Inc., Research Division, Ness Ziona, Israel; ${ }^{5}$ Department of Pharmacology and Therapeutics, McGill University, Montreal, QC, Canada and ${ }^{6}$ Department of Stomatology, Faculty of Dentistry, University of Montreal, Montreal, QC, Canada

${ }^{*}$ Corresponding author: A Di Polo, Department of Neuroscience, CHUM Research Center, University of Montreal, 900 Rue St-Denis, R09.480, Montreal, QC H2X 0A9, Canada. Tel: +1 5148908000 ext 31280; Fax: +1 514412 7936; E-mail: adriana.di.polo@ umontreal.ca

Abbreviations: RGC, retinal ganglion cell; mTOR, mammalian target of rapamycin; mTORC1, mammalian target of rapamycin complex 1; REDD2, regulated in development and DNA damage 2; REDD1, regulated in development and DNA damage 2; siRNA, short interfering RNA; CNS, central nervous system; TSC1/2, tuberose sclerosis complex 1/2; YFP, yellow fluorescent protein; NF-H, neurofilament H; Brn3a, brain-specific homeobox/POU domain protein 3a; p70S6K, p70 ribosomal S6 kinase; S6, ribosomal protein S6; pS6, phosphorylated ribosomal protein S6; TUJ1, tubulin isoform blll; INL, inner nuclear layer; GCL, ganglion cell layer; Cy3, cyanine 3; HIF-1 $\alpha$, hypoxia-inducible factor-1 alpha; PTEN, phosphatase and tensin homolog; ANOVA, one-way analysis of variance; $\mathrm{Hz}$, hertz

Received 25.6.14; revised 07.8.14; accepted 18.8.14; Edited by N Bazan; published online 26.9.14 
restored mTOR function in injured neurons and fully rescued their dendritic arbors, increasing dendritic length, field area and branch complexity. REDD2 depletion also abrogated pathologic RGC hyperexcitability and restored the light response properties of these neurons. Collectively, these data identify the REDD2-mTOR signaling pathway as a critical regulator of dendritic arbor morphology in adult central neurons undergoing axonal damage.

\section{Results}

RGC dendritic arbors retract soon after axonal injury and before cell death. To establish whether axonal injury induces structural changes in RGC dendrites, we carried out a detailed analysis of dendritic arbors in transgenic mice that selectively express yellow fluorescent protein (YFP) in RGCs under control of the Thy 1 promoter (Thy1-YFPH). ${ }^{18}$ In this mouse strain, RGC-specific YFP expression is detected in a small number of RGCs $(<1 \%)$, thus allowing visualization of individual dendritic arbors without interference from overlapping dendrites in neighboring neurons. A key question is to determine whether dendritic atrophy is a prerequisite or a consequence of RGC soma degeneration. For this purpose, we first established the time course of axotomy-induced RGC loss in Thy1-YFPH mice. Figure 1a shows that at 3 days after complete optic nerve axotomy, the intensity of the YFP label or the number of YFP-positive RGCs did not differ from those in non-injured (intact) retinas (injured: $63 \pm 4 \mathrm{RGCs}$; intact: $66 \pm 4$ RGCs, mean \pm S.E.M., analysis of variance (ANOVA), $P>0.05$; Table 1), whereas at 5 days after lesion there was substantial neuronal loss accounting for $35 \%$ of the RGC population (injured: $44 \pm 3$ RGCs, ANOVA, $P<0.001$ ). This time course of injury-induced RGC death was confirmed using an antibody against the transcription factor Brn3a, an RGC-specific marker ${ }^{19}$ (Figure 1b). Therefore, analysis of dendritic arbors was carried out at 3 days after axotomy, a time when no changes in the intensity or number of YFPlabeled RGCs were observed, and before overt neuronal soma loss.

Fourteen different morphologic RGC subtypes have been identified in the mouse retina, ${ }^{20,21}$ all of which are found in Thy1-YFPH transgenic retinas. ${ }^{21}$ Neurofilament $\mathrm{H}(\mathrm{NF}-\mathrm{H}$, SMI-32) is the only marker that labels several structural classes, specifically four subtypes identified by cluster analysis, ${ }^{21}$ which encompass a significant portion of the total RGC population (36\%: 1213 $\pm 101 \mathrm{RGCs} / \mathrm{mm}^{2}$ ). Therefore, YFP-positive RGCs that colabeled with an antibody against $\mathrm{NF}-\mathrm{H}$ and had a clearly identifiable axon were selected for dendritic arbor imaging and three-dimensional reconstruction. RGCs located in both central and peripheral retina were included in our analysis and measurements were performed blinded to manipulations. YFP+/NF-H+ RGCs had medium to large monostratified dendritic arbors with smooth dendrites lacking spines, a common feature of adult RGCs ${ }^{21}$ (Figures 1c-e). Following axotomy, RGC dendritic arbors were visibly smaller than those in non-injured, intact neurons (Figures if and $\mathrm{g}$ ). Analysis of total dendritic length and total dendritic area demonstrated a reduction of $15 \%(3707 \mu \mathrm{m})$ and $25 \%$ $\left(112 \times 10^{3} \mu \mathrm{m}^{2}\right)$, respectively, compared with control RGCs (length: $4320 \mu \mathrm{m}$; area: $150 \times 10^{3} \mu \mathrm{m}^{2}$ ) (Figures $1 \mathrm{~h}$ and $\mathrm{i}$ and Tables 1 and 2). Sholl analysis, which measures the number of dendrites that cross-concentric circles at increasing distances from the soma, revealed a leftward shift indicating a reduced arbor complexity in axotomized neurons (Figure 1j and Table 2). These changes were not dependent on retinal location or eccentricity. Our results demonstrate that RGC dendritic retraction occurs soon after axonal injury and before cell death in vivo.

Selective loss of mTOR activity in injured RGCs. mTOR interacts with intracellular partners to regulate several cellular processes, of which the best characterized is protein synthesis. mTOR phosphorylates the p70 ribosomal S6 kinase (p70S6K) leading to phosphorylation of the ribosomal protein S6, which stimulates mRNA translation rates. ${ }^{22}$ Antibodies that recognize phosphorylated S6(Ser240/244) are widely accepted functional readouts of mTOR activity. ${ }^{23}$ Therefore, to establish whether RGC dendritic retraction correlates with changes in mTOR activity in these neurons, we examined phospho-S6 ${ }^{\text {(Ser240/244) }}$ expression in intact and axotomized retinas. Phospho-S6 labeling was detected predominantly in two retinal cell populations, one located in the ganglion cell layer (GCL) and another in the outermost part of the inner nuclear layer (INL) (Figure 2a). Double labeling of phospho-S6 with an antibody against tubulin isoform $\beta$ III (TUJ1), a selective marker for RGCs in the retina, ${ }^{24,25}$ revealed that adult mouse $\mathrm{RGC}$ soma and dendrites are endowed with robust mTOR activity (Figures $2 \mathrm{~b}-\mathrm{i})$. Phospho-S6 labeling in the INL colocalized with the calcium-binding protein calbindin, a marker for horizontal cells (Figures $2 \mathrm{j}-\mathrm{l}$ ).

A marked decrease in phospho-S6-positive RGCs was observed at 3 days after axotomy, before the onset of cell death, whereas phospho-S6 expression in horizontal cells remained unchanged (Figures $2 \mathrm{~m}$ and $\mathrm{n}$ ). Colabeling of axotomized retinas with phospho-S6 and TUJ1 confirmed that phospho-S6 downregulation reflected loss of mTOR activity in RGCs and not RGC loss (Figures 2o-q). Quantification of the number of RGCs that expressed both phospho-S6 and TUJ1 with respect to all TUJ1-positive cells demonstrated that $\sim 50 \%$ of RGCs in the intact retina have detectable levels of mTOR activity (Figure $2 r$ and Table 1). Importantly, optic nerve injury led to $40 \%$ decrease in the number of RGCs expressing phospho-S6 (Figure $2 r$ ). In contrast, the number of horizontal cells expressing both phospho-S6 and calbindin did not change with axotomy (Figure 2s). These data indicate that selective damage to RGC axons leads to the downregulation of mTOR activity in these neurons but not in other retinal cells.

REDD2 is upregulated in injured RGCs. Inhibition of mTOR during stress occurs through stabilization or activation of the TSC1/TSC2 complex. REDD1 and REDD2 likely inhibit mTOR by controlling the release of TSC2 from its association with inhibitory factors, thereby stabilizing the interaction between TSC1 and TSC2. ${ }^{26}$ To test the hypothesis that REDD2 might be involved in mTOR inhibition in RGCs, we first examined the expression of REDD2 in intact and axotomized retinas. While low levels of REDD2 were detected in the GCL of non-injured retinas, a marked increase 

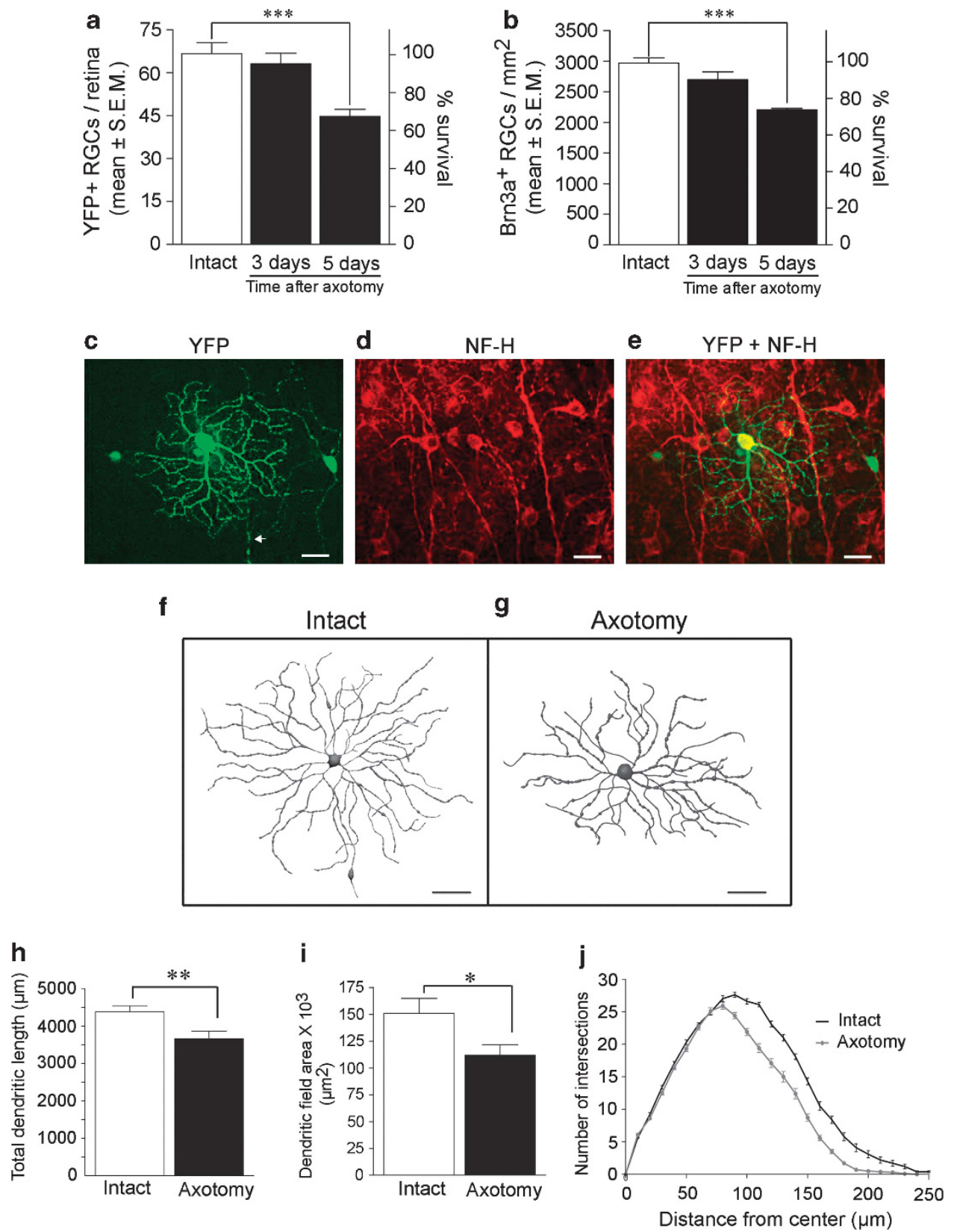

Figure 1 RGC dendritic arbors retract soon after axonal injury and prior to cell death. (a) Quantitative analysis of RGC densities showed no significant change in the number of YFP-positive RGCs at 3 days after axotomy, whereas substantial neuronal loss was observed at 5 days after lesion (axotomy 3 days: $n=7$; axotomy 5 days: $n=4$ ). (b) A similar pattern of RGC loss was observed using the RGC-specific marker Brn3a $(n=3)$. The density of RGCs in intact, uninjured retinas is shown as reference $(n=11)$. Data are expressed as mean \pm S.E.M. (ANOVA, ${ }^{* \star} P<0.001, n=3-11$ mice per group). (c-e) YFP-positive RGCs that colabeled with an antibody against NF-H and had clearly identifiable axons (arrow) were selected for dendritic arbor imaging and reconstruction. Scale bar: $25 \mu \mathrm{m}$. (f and $\mathbf{g}$ ) Three days after axotomy, RGCs had visibly smaller dendritic arbors than non-injured, intact neurons (axotomy: $n=21 \mathrm{cells}$; intact: $n=17 \mathrm{cells}$ ). Quantitative analysis of dendritic parameters revealed a significant reduction in total dendritic length (h), dendritic field area (i) and arbor complexity (j, Sholl analysis). Values are expressed as mean \pm S.E.M. (Student's $t$-test, ${ }^{* *} P<0.005,{ }^{*} P<0.05$, cells were analyzed from 5 mice per group)

in REDD2-positive labeling was observed at 3 days after axotomy (Figures $3 \mathrm{a}$ and $\mathrm{b}$ ). Colabeling of retinal sections with REDD2 and the RGC-specific marker Brn3a demonstrated that REDD2 expression selectively increases in injured RGCs (Figures 3c-e). REDD2 was also observed in the outer plexiform layer (OPL) and colocalized with horizontal cell proximal dendrites labeled with calbindin (Figures $3 a$ and $f-h$ ), but there was no detectable change in REDD2 expression in horizontal cell processes after axonal injury (Figures $3 b$ and $f-h$ ). REDD1, a family member that shares $38 \%$ homology with REDD2, ${ }^{27,28}$ was selectively expressed in the GCL (Figure 3i). Colabeling with the RGCspecific marker Brn3a confirmed that RGCs expressed REDD1 (Figures 3k and I), as reported previously. ${ }^{29}$ REDD2 upregulation in damaged RGCs was confirmed by western blot analysis of retinal homogenates as early as $48 \mathrm{~h}$ after 
Table 1 Number of animals $(N)$ used per experiment

\begin{tabular}{|c|c|c|c|}
\hline Group & Treatment & $N$ & Figure no. \\
\hline RGC survival analysis (YFP) & $\begin{array}{l}\text { Intact } \\
\text { Axotomy (3 days) } \\
\text { Axotomy (5 days) }\end{array}$ & $\begin{array}{r}11 \\
7 \\
4\end{array}$ & $\begin{array}{l}1 \mathrm{a} \\
1 \mathrm{a} \\
1 \mathrm{a}\end{array}$ \\
\hline RGC survival analysis (Brn3a) & $\begin{array}{l}\text { Intact } \\
\text { Axotomy (3 days) } \\
\text { Axotomy (5 days) }\end{array}$ & $\begin{array}{r}11 \\
3 \\
3\end{array}$ & $\begin{array}{l}1 b \\
1 b \\
1 b\end{array}$ \\
\hline Immunohistochemistry (NF-H+YFP) & Intact & 7 & $1 c-e$ \\
\hline Dendritic arbor analysis & $\begin{array}{l}\text { Intact } \\
\text { Axotomy (3 days) }\end{array}$ & $\begin{array}{l}5 \\
5\end{array}$ & $\begin{array}{l}1 \mathrm{~h}-\mathrm{j} \\
1 \mathrm{~h}-\mathrm{j}\end{array}$ \\
\hline Immunohistochemistry (phospho-S6+TUJ1) & $\begin{array}{l}\text { Intact } \\
\text { Axotomy (3 days) }\end{array}$ & $\begin{array}{l}4 \\
4\end{array}$ & $\begin{array}{c}2 a-i, m, r \\
2 a-i, n, o-r\end{array}$ \\
\hline Immunohistochemistry (phospho-S6+calbindin) & $\begin{array}{l}\text { Intact } \\
\text { Axotomy (3 days) }\end{array}$ & $\begin{array}{l}3 \\
3\end{array}$ & $\begin{array}{l}2 j-1, s \\
2 j-1, s\end{array}$ \\
\hline Immunohistochemistry (REDD2, REDD1) & $\begin{array}{l}\text { Intact } \\
\text { Axotomy (3 days) }\end{array}$ & $\begin{array}{l}3 \\
3\end{array}$ & $\begin{array}{c}3 a \\
3 b-k\end{array}$ \\
\hline Western blot analysis (REDD2, REDD1) & $\begin{array}{l}\text { Intact } \\
\text { Axotomy ( } 2 \text { days) } \\
\text { Axotomy ( } 3 \text { days })\end{array}$ & $\begin{array}{l}5 \\
4 \\
4\end{array}$ & $\begin{array}{l}3 \mathrm{l}-\mathrm{n} \\
3 \mathrm{l}-\mathrm{n} \\
3 \mathrm{l}-\mathrm{n}\end{array}$ \\
\hline $\begin{array}{l}\text { siRNA uptake (siCtl-Cy3+Fluorogold) } \\
\text { Western blot analysis (REDD2, REDD1) }\end{array}$ & $\begin{array}{l}\text { Intact+siCtl-Cy3 } \\
\text { Axotomy+siCtl } \\
\text { Axotomy+siREDD2 }\end{array}$ & $\begin{array}{l}4 \\
4 \\
5\end{array}$ & $\begin{array}{l}4 a-d \\
4 e-g \\
4 e-g\end{array}$ \\
\hline Immunohistochemistry (phospho-S6+Brn3a) & $\begin{array}{l}\text { Axotomy+siCtl } \\
\text { Axotomy+siREDD2 }\end{array}$ & $\begin{array}{l}4 \\
4\end{array}$ & $\begin{array}{c}4 k-n \\
4 h-j, 0\end{array}$ \\
\hline Immunohistochemistry (phospho-S6+calbindin) & $\begin{array}{l}\text { Axotomy+siCtl } \\
\text { Axotomy+siREDD2 }\end{array}$ & $\begin{array}{l}3 \\
3\end{array}$ & $\begin{array}{l}4 q \\
4 q\end{array}$ \\
\hline Dendritic arbor analysis & $\begin{array}{l}\text { Axotomy+siCtl } \\
\text { Axotomy+siREDD2 } \\
\text { Axotomy+siREDD2+Rapa } \\
\text { Intact+siREDD2 } \\
\text { Intact+rapamycin (Rapa) }\end{array}$ & $\begin{array}{l}5 \\
5 \\
4 \\
5 \\
5\end{array}$ & $\begin{array}{l}5 a, d-i \\
5 b, d-i \\
5 c, d-i \\
5 d-i \\
5 d-i\end{array}$ \\
\hline Electrophysiology & $\begin{array}{l}\text { Intact } \\
\text { Axotomy } \\
\text { Axotomy+siREDD2 } \\
\text { Axotomy+siCtl }\end{array}$ & $\begin{array}{r}7 \\
5 \\
5 \\
20\end{array}$ & $\begin{array}{c}\text { 6a-h, k, l } \\
\text { 6f, g, i, k, l } \\
\text { 6f, g, j, k, I } \\
\text { N/A }\end{array}$ \\
\hline RGC soma analysis & $\begin{array}{l}\text { Intact } \\
\text { Axotomy+siCtl } \\
\text { Axotomy+siREDD2 }\end{array}$ & $\begin{array}{l}5 \\
5 \\
5\end{array}$ & $\begin{array}{l}7 a \\
7 a \\
7 a\end{array}$ \\
\hline RGC survival analysis (Brn3a) & $\begin{array}{l}\text { Axotomy ( } 5 \text { days)+siREDD2 } \\
\text { Axotomy ( } 5 \text { days)+siCtl } \\
\text { Axotomy ( } 7 \text { days)+siREDD2 } \\
\text { Axotomy ( } 7 \text { days)+siCtl }\end{array}$ & $\begin{array}{l}4 \\
3 \\
5 \\
4\end{array}$ & $\begin{array}{l}7 b, f \\
7 c, f \\
7 d, f \\
7 e, f\end{array}$ \\
\hline
\end{tabular}

axotomy (Figures $3 \mathrm{~m}$ and $\mathrm{n}$ ). In contrast, the expression of REDD1 did not change after lesion (Figures $3 \mathrm{~m}$ and $\mathrm{o}$ ). These results demonstrate selective injury-induced REDD2 upregulation in RGCs.

REDD2 knockdown restores mTOR activity. To establish whether REDD2 upregulation mediated loss of mTOR activity in RGCs, we sought to reduce REDD2 expression by using siRNA followed by analysis of retinal phospho-S6. First, we examined whether siRNA delivered intraocularly was taken up by mouse RGCs. A single intravitreal injection of nontargeting (scrambled) Cy3-tagged control siRNA (siCtl-Cy3) resulted in Cy3 labeling in RGCs as early as $3 \mathrm{~h}$ after administration (Figure 4a). The colocalization of Cy3 and the retrograde tracer Fluorogold (FG), following FG application to the superior colliculus, confirmed that siRNA was rapidly taken up by RGCs (Figures $4 b-d$ ). Next, we assessed the ability of siRNAs against REDD2 (siREDD2) to knockdown retinal REDD2 protein expression in vivo. Western blot analysis of retinal homogenates from eyes that received siREDD2 at the time of axotomy showed a significant reduction of REDD2 protein, whereas non-tagged siCtl had no effect (Figures $4 e$ and f). Importantly, siREDD2 did not reduce the protein levels of REDD1, validating the specificity 
Table 2 Dendritic parameters

\begin{tabular}{|c|c|c|c|c|c|c|}
\hline Group & Treatment & $\begin{array}{l}\text { Total dendritic length }(\mu \mathrm{m}) \\
(\text { mean } \pm \text { S.E.M.) }\end{array}$ & $\begin{array}{c}\text { Dendritic field area } \\
\left(\times 10^{3} \mu \mathrm{m}^{2}\right) \\
\text { (mean } \pm \text { S.E.M. })\end{array}$ & $\begin{array}{c}\text { Sholl analysis } \\
\text { (area under curve) } \\
\text { (mean } \pm \text { S.E.M.) }\end{array}$ & $\begin{array}{l}\text { Number of } \\
\text { animals }(N)\end{array}$ & $\begin{array}{l}\text { Number of } \\
\text { RGCs }(n)\end{array}$ \\
\hline Intact & - & $4391.7 \pm 118.0$ & $149.7 \pm 10.5$ & $3413.8 \pm 128.6$ & 5 & 17 \\
\hline Intact & siREDD2 & $4348.4 \pm 275.1$ & $170.5 \pm 17.5$ & $3138.6 \pm 237.7$ & 5 & 19 \\
\hline Intact & Rapamycin & $4225.6 \pm 237.1$ & $144.4 \pm 20.2$ & $3057.1 \pm 241.8$ & 5 & 17 \\
\hline Axotomy & - & $3706.9 \pm 190.2$ & $111.8 \pm 9.9$ & $2682.0 \pm 128.6$ & 5 & 21 \\
\hline Axotomy & siCtl & $3613.6 \pm 181.5$ & $108.6 \pm 13.8$ & $2565.7 \pm 216.4$ & 5 & 18 \\
\hline Axotomy & siREDD2 & $4597.5 \pm 229.2$ & $163.5 \pm 9.7$ & $3713.8 \pm 138.5$ & 5 & 20 \\
\hline Axotomy & siREDD2+Rapamycin & $3523.0 \pm 185.0$ & $110.8 \pm 10.9$ & $2770.0 \pm 219.6$ & 4 & 19 \\
\hline
\end{tabular}
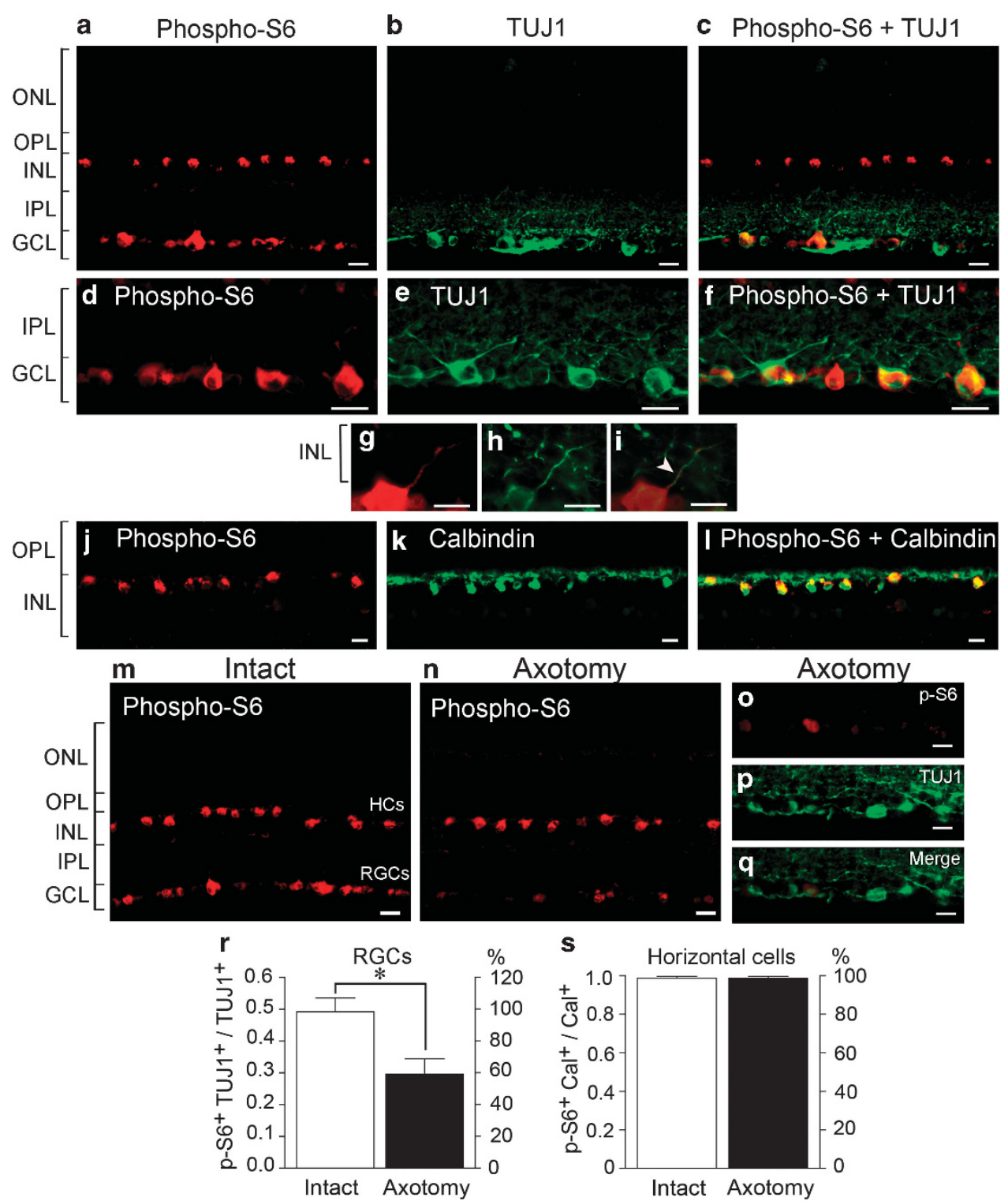

Figure 2 mTOR activity decreases in injured RGCs. (a) Phospho-S6 labeling was detected in neurons of the INL and GCL. (b-i) Colabeling of phospho-S6 with TUJ1, an RGC-specific marker, revealed mTOR activity in RGC soma and dendrites (arrowhead, i). (j-I) Phospho-S6 labeling in the INL colocalized with the calcium-binding protein calbindin, a marker for horizontal cells. ( $\mathbf{m}$ and $\mathbf{n}$ ) Loss of phospho-S6 in RGCs was observed at 3 days after axotomy, before the onset of cell death, whereas phospho-S6 expression in horizontal cells remained unchanged. (o-q) Phospho-S6 downregulation reflected loss of mTOR activity and not RGC death because these neurons were readily detected with TUJ1. (r) RGCs that expressed both phospho-S6 and TUJ1 with respect to all TUJ1-positive cells decreased after injury. (s) The number of horizontal cells expressing both phospho-S6 and calbindin did not change with axotomy. Values are expressed as mean \pm S.E.M. (Student's $t$-test, ${ }^{*} P<0.05, n=3-4$ mice per group). Scale bars: $(\mathbf{a}-\mathbf{I}$ and $\mathbf{o}-\mathbf{q})=25 \mu \mathrm{m}$ and $(\mathbf{m}$ and $\mathbf{n})=50 \mu \mathrm{m}$. ONL, outer nuclear layer; OPL, outer plexiform layer; IPL, inner plexiform layer; GCL, ganglion cell layer 

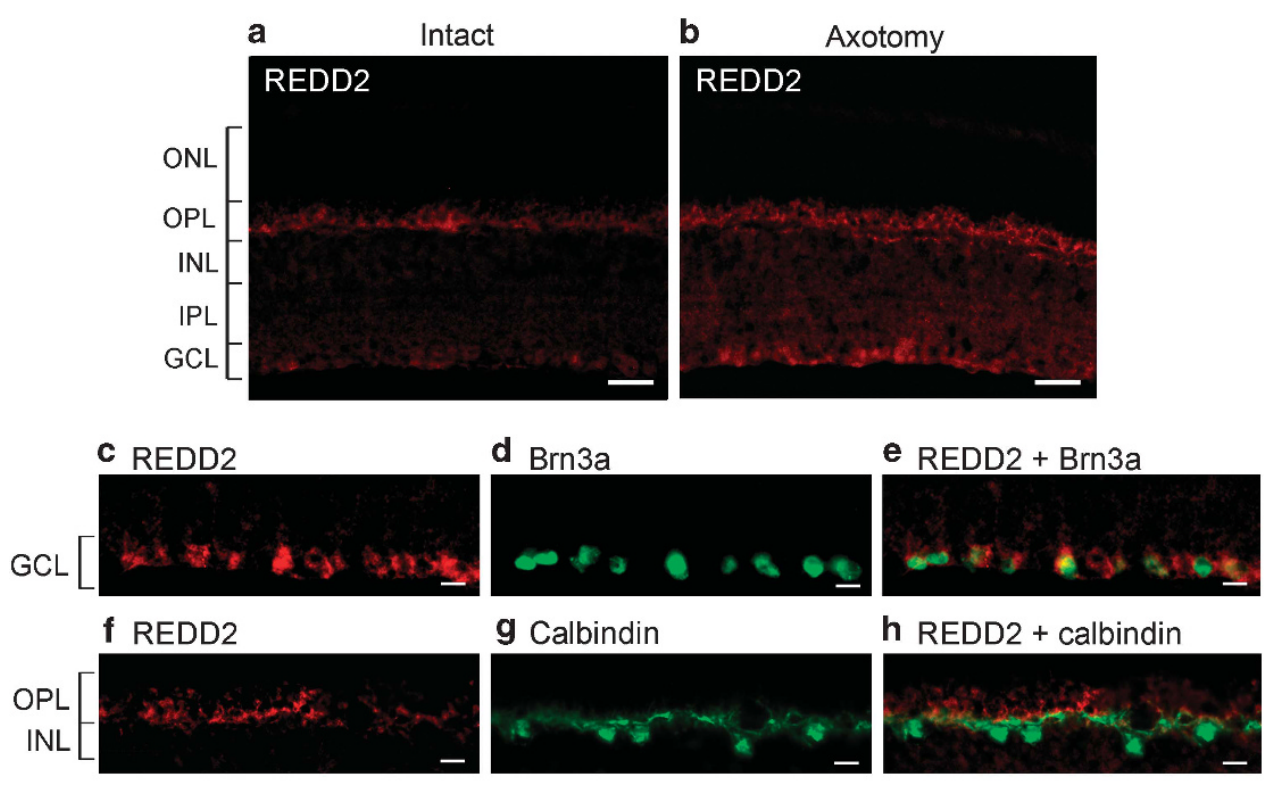

h REDD2 + calbindin
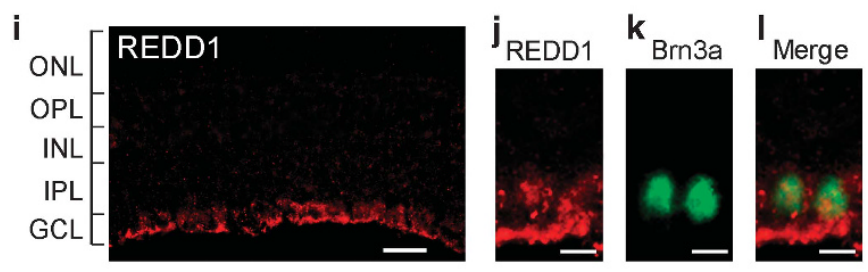

m
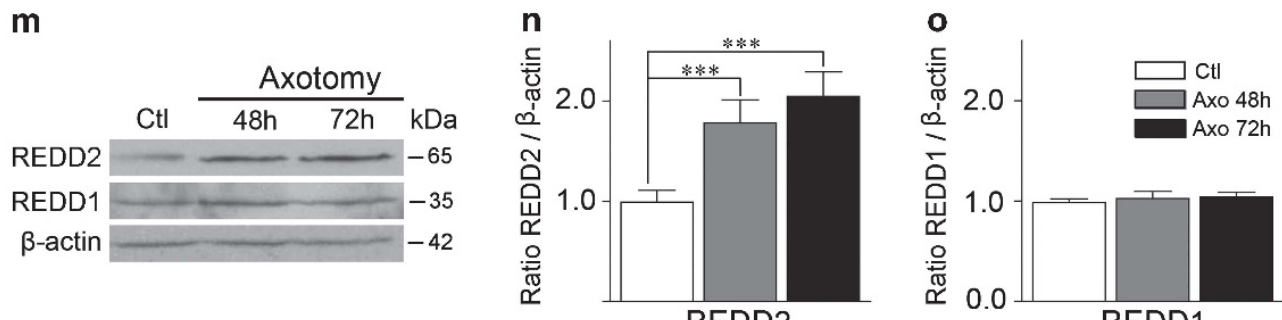

Figure 3 REDD2 is upregulated in injured RGCs. (a) Low levels of REDD2 were detected in the GCL of non-injured retinas. (b) In contrast, a marked increase in REDD2positive labeling was observed at 3 days after axotomy. (c-e) Colabeling with REDD2 and Brn3a demonstrated that REDD2 upregulation in injured RGCs. (a and $\mathbf{f}-\mathbf{h}$ ) REDD2 protein expression in the OPL colocalized with calbindin-positive horizontal cell proximal dendrites. (i-I) The family member REDD1 was selectively expressed in the GCL, and colabeling with the RGC-specific marker Brn3a confirmed its expression by RGCs. (m-0) Western blot and densitometric analyses demonstrated that REDD2 was upregulated as early as $48 \mathrm{~h}$ after axonal damage, whereas REDD1 remained unchanged. The lower panel represents the same blot as in the upper panels but probed with an antibody that recognizes $\beta$-actin used to confirm equal protein loading. Axo $48 \mathrm{~h}, A \times 072 \mathrm{~h}$ : analysis performed at 48 or $72 \mathrm{~h}$, respectively, after axotomy. Values are expressed as mean $\pm S$.E.M. (ANOVA, ${ }^{* * *} \mathrm{P}<0.001, n=3-5$ mice per group). Scale bars: ( $\mathbf{a}$ and $\left.\mathbf{b}\right)=50 \mu \mathrm{m}$ and $(\mathbf{c}-\mathbf{h})=25 \mu \mathrm{m}$. ONL, outer nuclear layer; OPL, outer plexiform layer; INL, inner nuclear layer; $\mathrm{IPL}$, inner plexiform layer; GCL, ganglion cell layer

of this siRNA (Figures $4 \mathrm{e}$ and $\mathrm{g}$ ). Immunohistochemistry of axotomized retinas confirmed that REDD2 downregulation occurred in RGCs, visualized with Brn3a, following treatment with siREDD2 but not siCtl (Figures $4 \mathrm{~h}-\mathrm{m}$ ). We next investigated whether siRNA-mediated knockdown of REDD2 resulted in recovery of mTOR function. Axotomized retinas treated with siREDD2 displayed a larger number of phosphoS6-positive RGCs compared with retinas injected with siCtl (Figures $4 \mathrm{n}$ and $\mathrm{o}$ ). Quantitative analysis demonstrated a $45 \%$ increase in the number of axotomized RGCs expressing phospho-S6 in the presence of siREDD2 compared with control retinas (Figure $4 p$ and Table 1), whereas the number of phospho-S6-positive horizontal cells did not change
(Figure 4q). These data demonstrate that REDD2 knockdown increases mTOR activity in injured RGCs, and suggests that axotomy-induced REDD2 upregulation leads to the loss of mTOR function in these neurons.

REDD2-dependent increase in mTOR function rescues dendrites. We asked whether siREDD2-induced upregulation of mTOR activity had an effect on dendritic arbor structure after axonal injury. Characterization of neuronal morphology at 3 days after axotomy demonstrated that siREDD2-treated retinas contained RGCs with longer dendrites and more elaborate arbors than control retinas treated with siCtl (Figures 5a and b). Coadministration of siREDD2 

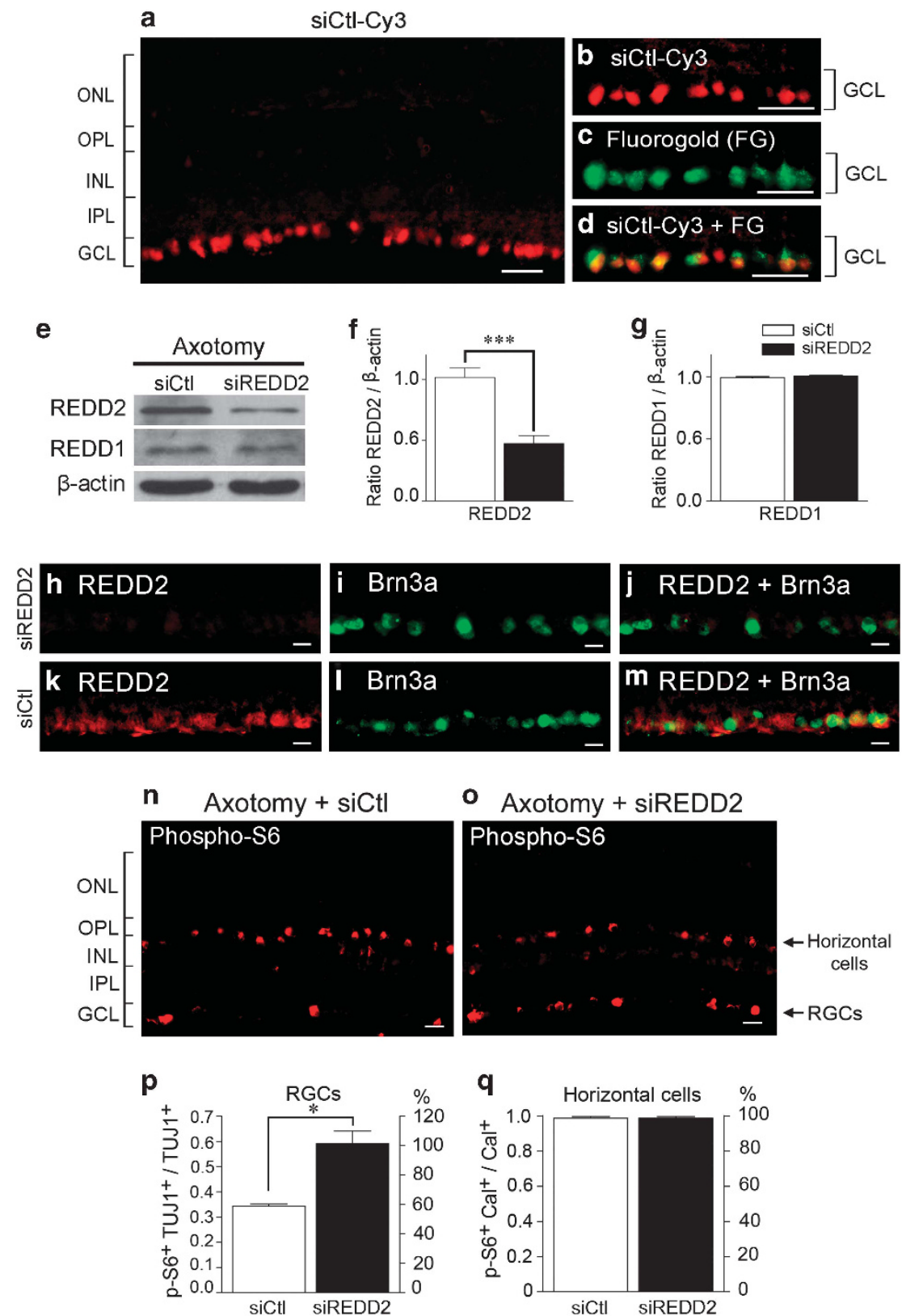

Figure 4 REDD2 knockdown restores mTOR activity. (a-d) Intravitreal delivery of siCtl-Cy3 resulted in rapid and effective uptake by RGCs, visualized with the retrograde tracer FG. (e and f) Western blot and densitometric analyses showed that intravitreal delivery of siRNA against REDD2 (siREDD2) led to a reduction of retinal REDD2 protein, while siCtl had no effect (Student's $t$-test, ${ }^{* \star *} P<0.01, n=4-5$ mice per group). (e and $\mathbf{g}$ ) siREDD2 did not decrease or increase the protein levels of REDD1, confirming the specificity of the siRNA. The lower panel represents the same blot as in the upper panels but probed with an antibody that recognizes $\beta$-actin used to confirm equal protein loading. (h-j) siRNA-mediated knockdown of REDD2 occurred in RGCs, visualized with Brn3a, but not in retinas treated with siCtl (k-m). (n and $\mathbf{o})$ Axotomized retinas treated with siREDD2 had more phospho-S6-positive RGCs compared with siCtl-treated retinas. (p) Quantitative analysis demonstrated a 45\% increase in the number of TUJ1-positive axotomized RGCs expressing phospho-S6 in the presence of siREDD2 compared with control retinas. The number of phospho-S6-positive horizontal cells did not change (q). Values are expressed as mean \pm S.E.M. (Student's t-test, ${ }^{*} P<0.05, n=4$ mice per group). Scale bars: $(\mathbf{a}-\mathbf{d})=50 \mu \mathrm{m}$; $(\mathbf{h}-\mathbf{0})=25 \mu \mathrm{m}$. ONL, outer nuclear layer; OPL, outer plexiform layer; INL, inner nuclear layer; IPL, inner plexiform layer; GCL, ganglion cell layer

and rapamycin, an inhibitor of the mTOR complex 1 (mTORC1), ${ }^{30}$ completely blocked the effect of siREDD2 on dendritic rescue, suggesting that this response was mTORC1-specific (Figure 5c). Quantitative analysis of dendritic arbor parameters revealed that siREDD2 protected $32 \%$ of the total dendritic length and $34 \%$ of the dendritic field area from injury-induced damage compared with siCtl or a combination of siREDD2 and rapamycin (Figures $5 \mathrm{~d}$ and $\mathrm{f}$ and Table 2). Administration of siREDD2 or rapamycin alone in non-injured, intact retinas did not elicit significant changes in dendritic length or field area (Figures $5 e$ and g). Dendritic arbor reconstruction and measurements were carried out blinded to treatments.

To assess the contribution of proximal and distal dendrites to axotomy-induced changes and the effect of siREDD2, we examined the dendritic length of proximal dendrites (orders 1-3) 

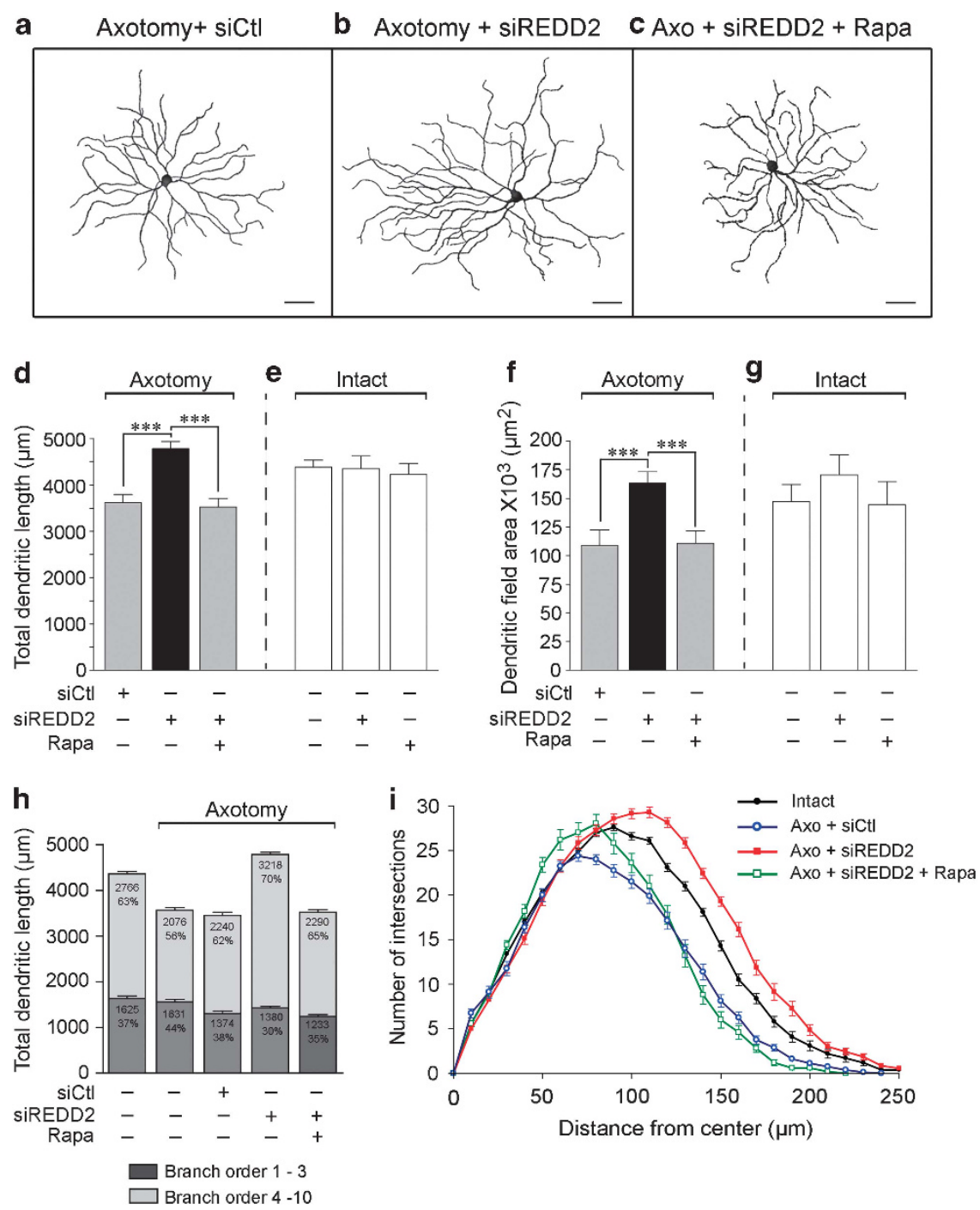

Figure 5 REDD2-dependent increase in mTORC1 function rescues dendritic arbors. (a and $\mathbf{b})$ siREDD2-treated RGCs $(n=20$ cells) have elaborate arbors with longer dendrites than control neurons treated with siCtl ( $n=18$ cells). (c) Coadministration of siREDD2 with rapamycin (Rapa, $n=19$ cells), an inhibitor of the mTORC1, blocked the effect of siREDD2 on dendritic morphology (4-5 mice per group). ( $\mathbf{d}$ and $\mathbf{f}$ ) The total dendritic length and field area increased in siREDD2-treated retinas compared with controls treated with siCTL or a combination of siREDD2 and rapamycin. (e and $\mathbf{g})$ Administration of siREDD2 ( $n=19$ cells) or rapamycin alone $(n=17$ cells) did not elicit changes in dendritic length or field area of non-injured (intact) neurons (4-5 mice per group). (h) Analysis of the contribution of proximal dendrites (orders 1-3) and distal dendrites (orders 4-10) showed that injury-induced changes and the response to siREDD2 occurred primarily in distal dendrites. (i) Sholl analysis revealed an increase in arbor complexity in axotomized siREDD2-treated RGCs compared with cells exposed to siCtl or a combination of siREDD2 and rapamycin. All analyses were performed at 3 days after axotomy. Values are expressed as the mean \pm S.E.M. (ANOVA, $\left.{ }^{* *} P<0.001\right)$. See Table 2 for all $N$ values. Scale bars: $(\mathrm{a}-\mathrm{c})=50 \mu \mathrm{m}, \mathrm{Axo}$, axotomy

compared with distal dendrites (orders 4-10). This analysis demonstrated that most of the changes occurring after axotomy and following modulation of the REDD2-mTOR pathway take place in distal dendrites (Figure 5h). Furthermore, Sholl analysis revealed a rightward shift indicative of increased arbor complexity in axotomized siREDD2-treated retinas with respect to axotomized retinas treated with siCtl or a combination of siREDD2 and rapamycin (Figure 5i). Increased arbor complexity was more apparent at $>100 \mu \mathrm{m}$ from the cell soma, consistent with changes taking place in distal dendritic segments. Intriguingly, the dendritic arbors of injured RGCs that received siREDD2 displayed higher complexity than those in intact, non-injured retinas without treatment (Figure 5i, red curve versus black curve; Table 2).
siREDD2 administration to intact eyes did not alter dendritic arbor complexity (not shown). These data identify the REDD2-mTORC1 axis as a critical regulator of RGC dendritic arbor morphology in injured neurons, and provide evidence that REDD2-dependent increase in mTORC1 activity rescues $R G C$ dendrites after axotomy.

siREDD2-mediated mTOR activation restores neuronal function. To assess the impact of dendritic arbor rescue on RGC function, we performed whole-cell recordings from single ON-center RGCs at 3 days after axotomy and concurrent intraocular injection of siREDD2 or siCtl at the time of injury. Retinas were placed in the recording chamber with the GCL facing up and visualized with epifluorescence, 

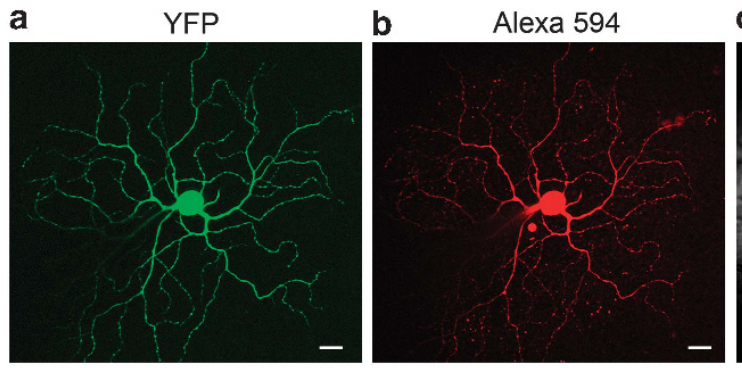

c DIC illumination
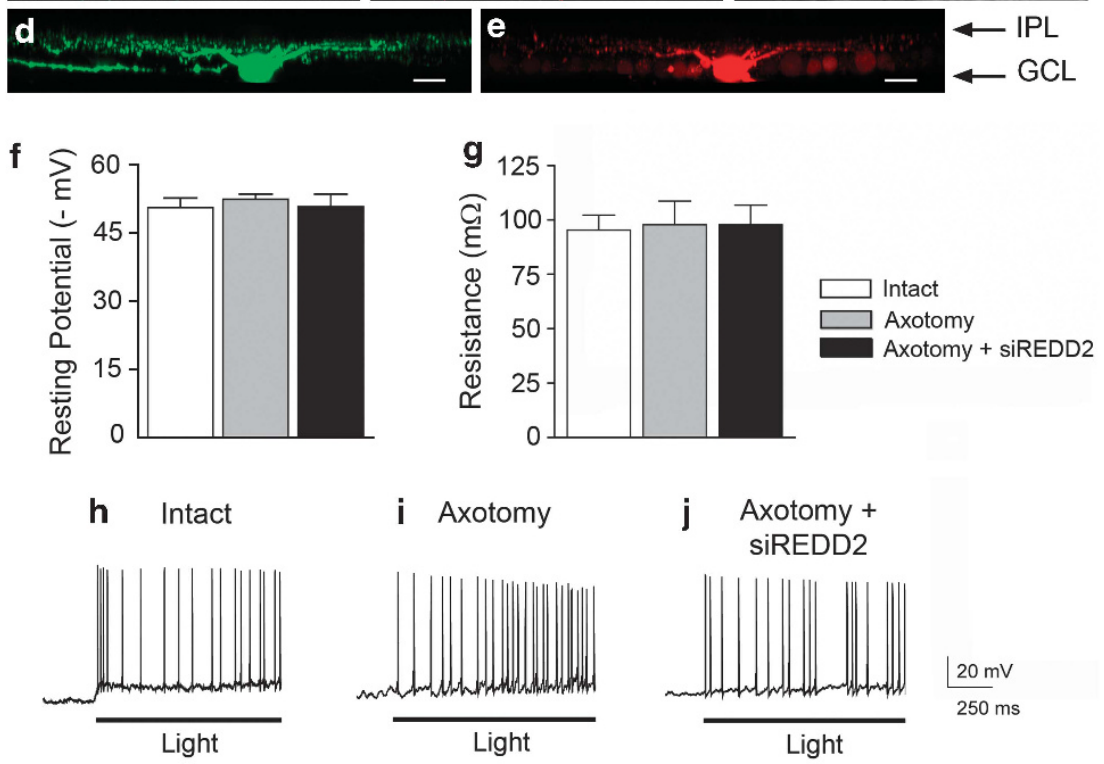

$\mathbf{k}$
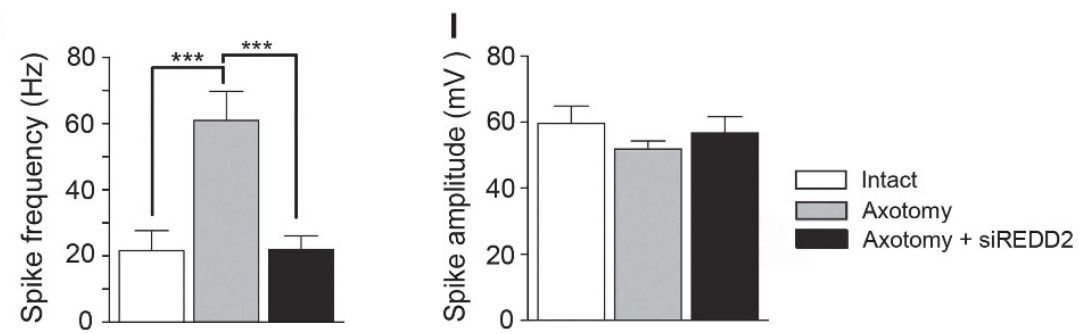

Figure 6 siREDD2-mediated mTOR activation restores RGC function. (a-c) Whole-cell recordings were obtained from ON-center YFP-positive RGCs visualized with epifluorescence and infrared differential interference contrast (DIC) optics to position the recording electrode. (b, $\mathbf{d}$ and $\mathbf{e})$ The identity of each recorded cell was confirmed following injection of Alexa Fluor 594 through the recording pipette. Analysis of RGC intrinsic properties, including membrane resting potential (f) and resistance (g), did not reveal significant differences between intact and axotomized neurons with or without siREDD2 treatment. ( $h$ and i) Light stimulation demonstrated an increase in the frequency of action potentials elicited by axotomized RGCs ( $n=7$ cells) compared with non-injured controls ( $n=7$ cells). ( $j$ and $\mathbf{k}$ ) siREDD2 treatment restored the light-induced firing frequency to levels similar to those recorded from intact neurons ( $n=7$ cells). (I) No change in the amplitude of action potentials was observed. Values are expressed as the mean \pm S.E.M. (ANOVA, $\left.{ }^{* *} P<0.001\right)$. Cells were recorded from 5 to 7 mice per group. Scale bars: $(\mathrm{a}-\mathrm{e})=20 \mu \mathrm{m}$

to identify YFP-labeled RGCs, as well as infrared differential interference contrast optics to position the recording electrode. The identity of each recorded cell and its pattern of dendritic arborization in the inner plexiform layer was confirmed post hoc following injection of Alexa Fluor 594 through the recording pipette (Figures 6a-e). Analysis of RGC intrinsic properties, including membrane resting potential and resistance, did not reveal significant differences between intact and axotomized neurons with or without siREDD2 treatment (Figures $6 f$ and g). In contrast, light stimulation elicited firing at a much higher frequency in axotomized RGCs compared with non-injured controls (intact: $22 \pm 6 \mathrm{~Hz}$; axotomy: $61 \pm 9 \mathrm{~Hz}, \quad$ mean \pm S.E.M.;
Figures $6 \mathrm{~h}$ and i). Remarkably, siREDD2 treatment restored the light-induced firing frequency in axotomized RGCs to levels similar to those recorded from intact neurons (axotomy +siREDD2: $22 \pm 4 \mathrm{~Hz}$; Figures $6 \mathrm{j}$ and $\mathrm{k}$ and Table 1). No significant change was observed in the amplitude of action potentials (Figure 6I). Intriguingly, attempts to record from axotomized RGCs treated with siCtl or phosphate-buffered saline (PBS) were unsuccessful. These cells had low resting potentials and did not fulfill a minimal criteria for consistency in firing rates ( $>40$ experiments). Taken together, our results indicate that axotomy leads to early RGC hyperexcitability and that siREDD2-mediated rescue of dendritic arbors restores the light response properties of these neurons. 
mTOR activation extends neuronal survival. RGC apoptosis after axonal injury has been associated with soma and nuclear shrinkage,$^{31}$ and mTOR is known to regulate soma

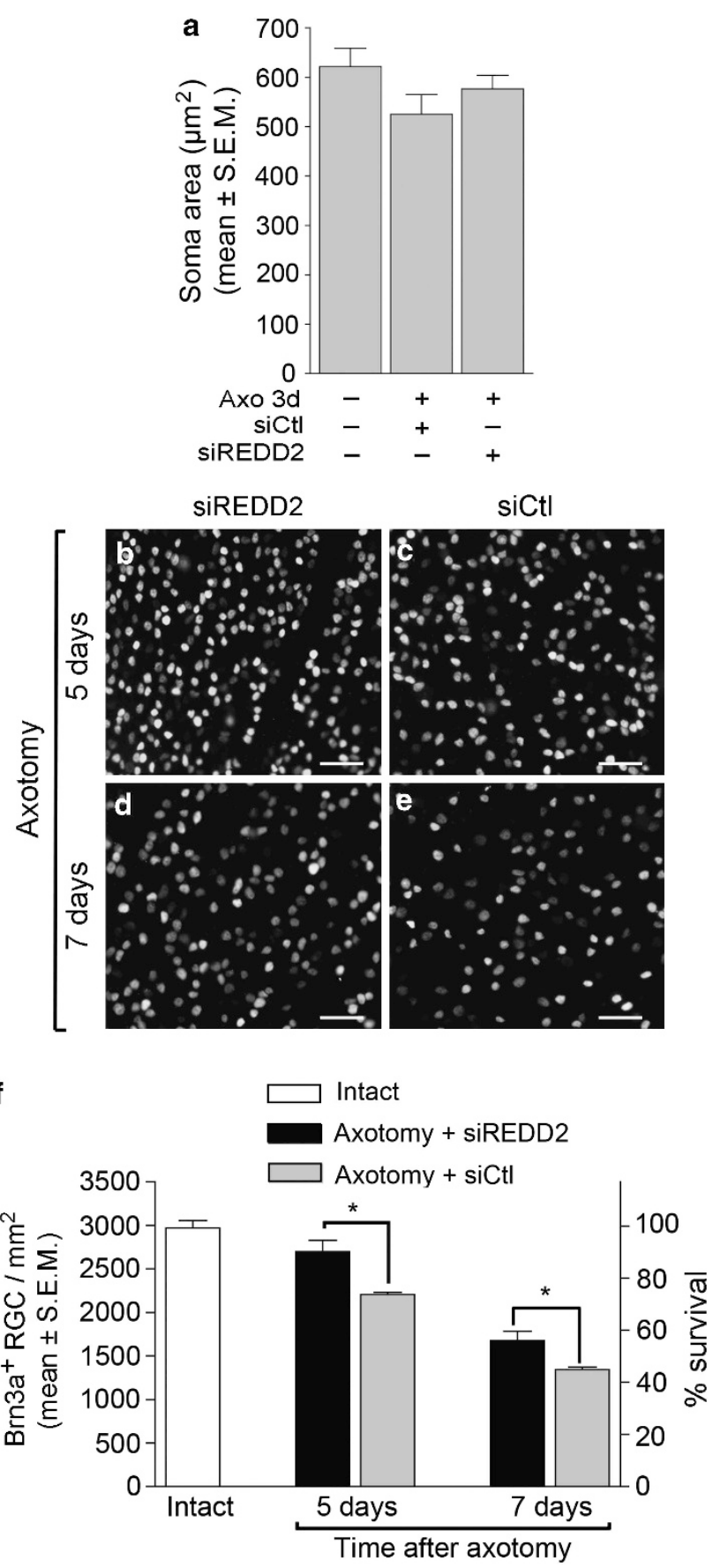

Figure 7 mTOR activation extends neuronal survival. (a) No significant change in RGC soma size was found at 3 days after axotomy with or without siREDD2 (Axo alone: $n=18$ cells; Axo+siREDD2: $n=20$ cells; intact: $n=17$ cells; $3-5$ mice per group). (b-e) Flat-mounted retinas from eyes treated with siREDD2 showed higher densities of Brn3a-labeled RGCs than those treated with siCtl. (f) Quantitative analysis demonstrated that siREDD2 promoted substantial RGC survival relative to siCtl-treated eyes at 5 and 7 days after axotomy. Values are expressed as RGC densities (RGCs $/ \mathrm{mm}^{2}$; mean \pm S.E.M., ANOVA, ${ }^{*}<0.05, n=3-5$ mice per group). The density of RGCs in intact, uninjured retinas is shown as reference $(100 \%$ survival). Scale bars: (b-e) $=50 \mu \mathrm{m}$ size in neurons. ${ }^{32}$ Therefore, we first examined RGC soma size after axotomy and whether it was susceptible to REDD2dependent mTOR activity. Our data show that there was no significant change in RGC soma size at 3 days after axotomy in the presence or absence of siREDD2 (Figure $7 a$ and Table 1). To determine if siREDD2-mediated rescue of dendritic arbors had an effect on neuronal survival, we examined retinas at 5 and 7 after axotomy. Flat-mounted retinas from eyes treated with siREDD2 at the time of axotomy consistently showed higher densities of Brn3alabeled RGCs than those treated with siCtl (Figures $7 \mathrm{~b}-\mathrm{e}$ ). Quantitative analysis demonstrated that siREDD2 promoted substantial RGC survival relative to siCtl-treated eyes at 5 days (siREDD2: $91 \%$ survival, $2700 \pm 128 \mathrm{RGCs} / \mathrm{mm}^{2}$; siCtl: $74 \%, 2207 \pm 22 \mathrm{RGCs} / \mathrm{mm}^{2}$ ) and 7 days (siREDD2: $56 \%, 1675 \pm 108 \mathrm{RGCs} / \mathrm{mm}^{2}$; siCtl: $45 \%, 1344 \pm 27 \mathrm{RGCs} /$ $\mathrm{mm}^{2}$ ) after optic nerve injury (Figure $7 f$ and Table 1). Taken together, these data suggest that mTOR-mediated protection of dendritic arbors attenuates RGC loss after axonal damage.

\section{Discussion}

Abnormalities in dendritic structure are a characteristic feature of many brain diseases, yet the molecular mechanisms leading to dendritic pathology in injured neurons are poorly understood. In this regard, the data presented here using the adult mouse visual system support several novel conclusions. First, we show that dendritic retraction occurs rapidly in a substantial population of RGCs, before overt cell death, and as a direct consequence of axonal injury. Second, we demonstrate that damage to RGC axons induces expression of REDD2 coinciding with strong inhibition of mTOR activity in these neurons. Third, we show that REDD2 upregulation underlies the aberrant dendritic phenotype because siRNAmediated ablation of REDD2 restores mTOR activity and rescues RGC dendritic arbor structure and complexity. Lastly, REDD2 depletion leading to mTOR activation re-establishes the light response properties of injured RGCs and extends their survival. Taken together, these data suggest a novel role for REDD2 in the regulation of dendritic morphology through modulation of mTOR activity after axonal damage.

Dendrites are extremely dynamic during development, expanding and retracting rapidly in response to intrinsic and environmental cues, ${ }^{33,34}$ but they become stable by adulthood and display little or no structural changes over extended time periods. ${ }^{35}$ The stability of dendritic arbors is believed to be compromised following injury or during neurodegeneration. For example, the selective death of RGCs is a cardinal feature of glaucoma, ${ }^{36}$ and shrinkage of RGC dendritic arbors has been observed in primate, cat and rodent models of this disease ${ }^{37-43}$ as well as in human glaucomatous retinas. ${ }^{44}$ The primary site of damage in glaucoma is believed to be at RGC axons in the optic nerve head. ${ }^{45}$ Consistent with this, we show that axotomy triggers rapid dendritic retraction, a finding that is in agreement with early dendritic changes observed after optic nerve crush. ${ }^{46,47}$ In spite of the large morphologic diversity of RGC dendritic arbors in the mouse retina, ${ }^{20,21}$ few molecular markers for discrete RGC subtypes have been identified and include NF-H, melanopsin and junctional adhesion molecule $B^{21,48,49}$ Among these, only NF-H labels several structural 
classes identified by cluster analysis and encompass a substantial RGC population. ${ }^{21,48}$ It has been proposed that different RGC subtypes display distinct susceptibilities to injury. In the axotomized feline retina, a cells, which are endowed with large somata and dendritic arbors, undergo a significant decrease in dendritic field size, whereas $\beta$ cells with medium-sized somata and more compact dendritic trees are less affected. ${ }^{50}$ Our results show that NF-H-positive RGCs, which comprise cells with medium- to large-sized dendritic arbors, undergo substantial atrophy after axotomy similar to $a$ cells. A previous study reported dendritic atrophy in $\mathrm{NF}-\mathrm{H}-$ positive RGCs at 2 months after laser-induced ocular hypertension, a time when there is significant soma and axonal loss, but only in the superior quadrant of hypertensive eyes. ${ }^{43}$ We observed dendritic arbor shrinkage in all retinal quadrants that was independent of retinal eccentricity, which may reflect differences between these injury models and also that our analysis was carried out early after axonal injury at a time preceding massive neurodegeneration.

The identification of pathways that contribute to RGC dendritic arbor maintenance is essential to understand the molecular basis of pathologic changes and to identify potential therapeutic targets. Our data suggest that the REDD2mTORC1 pathway is critical for dendritic stability in adult RGCs. We show that damage to RGC axons leads to cellspecific increase of REDD2, mTORC1 inhibition and dendritic retraction. REDD2 is strongly upregulated by hypoxia, via the hypoxia-inducible factor-1a (HIF-1a), ${ }^{28}$ as well as oxidative and osmotic stress. ${ }^{15,16,51}$ Optic nerve damage increases HIF- $1 a$ and reactive oxygen species in RGCs, ${ }^{52,53}$ which may account for the axotomy-induced upregulation of REDD2 reported here. Given that REDD2 is a strong inhibitor of mTOR, we asked whether injury-induced REDD2 upregulation led to mTOR inhibition and dendritic retraction. We show that adult RGCs are endowed with constitutive mTOR activity that is markedly reduced after axotomy, consistent with a study showing reduced mTOR in RGCs following optic nerve crush. ${ }^{54}$ Our loss of function experiments using siRNAmediated REDD2 knockdown demonstrate selective restoration of mTOR activity in injured RGCs accompanied by rescue of dendritic arbors. Moreover, rapamycin administration completely obliterated the effect of REDD2 depletion on dendritic rescue. Our data suggest that REDD2-dependent loss of mTORC1 function underlies RGC dendritic shrinkage, and that mTORC1 is required for the stability of adult RGC dendrites.

Recent work supports a role for mTOR in RGC axon regeneration. ${ }^{55,56}$ For example, deletion of the phosphatase and tensin homolog or TSC1, both negative regulators of mTOR, promoted robust RGC axon regeneration along the injured optic nerve tract. ${ }^{54,57}$ More recently, Leibinger et al. ${ }^{58}$ showed that inflammatory stimulation prevented the axotomyinduced decline of mTOR activity in RGCs and demonstrated that mTOR signaling is important to sustain RGCs in an active regenerative state. Further research is required to identify the mTOR-specific targets that contribute to RGC axon regrowth or dendritic stability. A central role of $\mathrm{mTOR}$ is to regulate protein translation; thus, it is possible that $\mathrm{mTORC} 1$ mediates the translation of structural or signaling proteins in dendrites, to ensure arbor maintenance, and in axons, to promote regeneration. Several molecules that contribute to dendritic arbor stability during development have been identified including the microtubule-associated proteins $1 \mathrm{~A}$ and 2 , integrin $a 3 \beta 1$, calcium/calmodulin-dependent protein kinase II, nuclear Dbf2-related kinases and the guanine deaminase cypin. ${ }^{35}$ It would be of future interest to assess whether these molecules are translational targets of mTOR and if they are dysregulated in the context of injury in the adult CNS. Alternatively, mTOR may directly regulate protein-protein interactions required for dendritic maintenance. Indeed, mTOR has been shown to enhance the interaction between microtubules and actin-binding proteins required for proper dendritic arbor morphology, ${ }^{59}$ suggesting a role beyond that of protein translation. ${ }^{60}$

Our electrophysiologic data demonstrate that, soon after injury, RGCs display increased firing rates characteristic of hyperexcitable neurons. This finding is consistent with a recent study showing a significant increase in RGC spontaneous firing of action potentials in a mouse model of microbeadinduced ocular hypertension. ${ }^{61}$ This RGC hyperactivity contrasts with reduced spontaneous firing recorded using extracellular multielectrode arrays in a similar glaucoma model in mice, ${ }^{42}$ a discrepancy that may reflect differences in methodology and cell sampling. Remarkably, siREDD2 treatment restored firing rates to levels similar to those found in intact, non-injured neurons. Intriguingly, we were not able to obtain whole-cell recordings from axotomized RGCs treated with siCtl. We cannot conclude that siCtl is toxic to cells because we were not able to record from PBS-injected eyes either. Our data rather suggest that the combination of axotomy and intraocular injection has a detrimental effect on the electrophysiologic properties of RGCs, a response that is overcome by siREDD2. The loss of light-triggered responses by RGCs subjected to concomitant axotomy and intravitreal injection suggests that multiple eye injuries impair RGC function, an observation that deserves further investigation. The excitability of a neuron is the result of a balance between several factors including resting potential, input resistance and soma size. The observed dendritic abnormalities reported here were not accompanied by detectable changes in any of these parameters; therefore, it is unlikely that axotomy-induced hyperexcitability and the effect of siREDD2 are the result of changes in intrinsic membrane properties or soma size. Our data suggest that functional deficits most likely derive from injury-induced changes in dendritic integrity and rearrangement of synaptic inputs, with hyperexcitability resulting from an increase in excitatory connections or a decrease in inhibitory synapses. Of interest, mTOR has been previously shown to suppress dendritic translation of the potassium channel

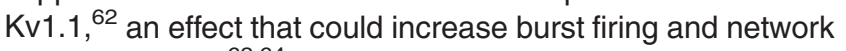
synchronization. ${ }^{63,64}$ More recently, TSC1-mTOR signaling was shown to regulate the balance between excitatory and inhibitory synaptic transmission, which, when defective, led to hippocampal network hyperactivity. ${ }^{65}$

In conclusion, our data support a model in which axonal injury-induced upregulation of the stress-responsive REDD2 leads to mTOR inhibition triggering early dendritic arbor retraction, neuronal dysfunction and subsequent death of adult retinal neurons. Our findings shed light onto a novel 
mechanism regulating dendritic pathology, which may be relevant for neurodegenerative diseases including glaucoma.

\section{Materials and Methods}

Experimental animals. Animal procedures were performed in accordance with the guidelines of the University of Montreal and the Canadian Council on Animal Care for the use of experimental animals (http://www.ccac.ca). All surgeries were carried out in adult B6.Cg.Tg[Thy1-YFPH]2Jrs/J mice (Jackson Laboratory, Bar Harbor, ME, USA) or wild-type litter mate controls maintained in our animal facility. The number of animals used in each experiment is indicated in Table 1 and in the figure legends.

Axonal injury. Axonal injury was induced by complete transection (axotomy) of the mouse optic nerve leading to apoptotic loss of RGCs. ${ }^{66}$ The left optic nerve was transected at $0.5-1 \mathrm{~mm}$ from the optic nerve head avoiding damage to the ophthalmic artery. The right eye was never operated on and served as intact control. Fundus examination was performed after axotomy and before the mice were killed to verify the integrity of the retinal circulation after surgery. Animals with compromised blood supply were excluded from the study.

\section{Immunohistochemistry}

Flat-mounted retinas: Mice were perfused transcardially with $4 \%$ paraformaldehyde (PFA), the eyes were immediately collected and the retinas were carefully dissected out. Retinas were free floated for $30 \mathrm{~min}$ in blocking solution: $10 \%$ normal goat serum (NGS), $2 \%$ Triton X-100 and $0.5 \%$ dimethyl sulfoxide (DMSO) in PBS. Retinas were then incubated for $72 \mathrm{~h}$ at $4{ }^{\circ} \mathrm{C}$ in blocking solution (2\% NGS, $2 \%$ Triton X-100, $0.5 \% \mathrm{DMSO}$ ) containing each of the following primary antibodies: SMl-32 (NF-H, $10 \mu \mathrm{g} / \mathrm{ml}$; Sternberger Monoclonals, Baltimore, MD, USA), GFP $(4 \mu \mathrm{g} / \mathrm{ml}$; Sigma-Aldrich, Oakville, ON, Canada) or Brn3a $(0.3 \mu \mathrm{g} / \mathrm{ml}$; Santa Cruz Biotechnologies, Santa Cruz, CA, USA). Retinas were washed and incubated with secondary antibodies: anti-mouse Alexa Fluor $594(2 \mu \mathrm{g} / \mathrm{ml}$; Molecular Probes, Eugene, OR, USA), anti-rabbit FITC (1:1000; Sigma-Aldrich) or anti-goat Alexa Fluor 594 (2 $\mu \mathrm{g} / \mathrm{ml}$; Molecular Probes). The retinas were washed and flat mounted on glass slides with the RGC layer side up for visualization using a fluorescent microscope (Zeiss AxioSkop 2 Plus; Carl Zeiss Canada, Kirkland, QC, Canada). Retinal cross-sections: Animals were perfused transcardially with 4\% PFA and retinal cryosections $(16 \mu \mathrm{m})$ were prepared as previously described by us. ${ }^{67}$ Some cryosections were prepared from eyes labeled with the retrograde tracer $F G$ (Fluorochrome, Englewood, CO, USA), which was applied to the superior colliculus 1 week before optic nerve axotomy as described by us. ${ }^{66}$ Each of the following primary antibodies were added to the retinal sections in blocking solution ( $3 \%$ bovine serum albumin, $0.3 \%$ Triton $\mathrm{X}-100$ ) and incubated overnight at $4{ }^{\circ} \mathrm{C}$ : phospho-S6 (Ser 240/244, 1: 200; Cell Signaling Technology, Boston, MA, USA), $\beta$ Ill-tubulin (TUJ1, 1:400; Sigma-Aldrich), calbindin (1:200; Swant, Marly, Switzerland), REDD2 ( $5 \mu \mathrm{g} / \mathrm{ml}$; Biorbyt, San Francisco, CA, USA), REDD1 $(1 \mu \mathrm{g} / \mathrm{ml}$; ProSci Inc., Poway, CA, USA) or Brn3a (1 $\mu \mathrm{g} / \mathrm{ml}$; Santa Cruz Biotechnologies). The secondary antibodies used were as follows: anti-rabbit Cy3 $(1.5 \mu \mathrm{g} / \mathrm{ml}$; SigmaAldrich), anti-mouse FITC (1:1000; Sigma-Aldrich), anti-rabbit Alexa Fluor 594 $(2 \mu \mathrm{g} / \mathrm{ml}$; Molecular Probes) or anti-goat Alexa Fluor $488(2 \mu \mathrm{g} / \mathrm{ml}$; Molecular Probes). Fluorescent labeling was observed with a Zeiss AxioSkop 2 Plus (Carl Zeiss Canada).

Neuronal survival. Mice were killed by transcardial perfusion with $4 \%$ PFA, the retinas were removed and flat mounted with vitreal side up on a glass slide for examination of the GCL. YFP-labeled RGCs were counted within three square areas at distances of $0.25,0.625$ and $1 \mathrm{~mm}$ from the optic disc in each of the four retinal quadrants for a total of 12 retinal areas. RGC densities were confirmed using flat-mounted retinas labeled with Brn3a (Santa Cruz Biotechnologies) as described. ${ }^{68}$ Fluorescence was examined with a Zeiss Axioskop 2 Plus microscope (Carl Zeiss Canada), and pictures were captured with a CCD video camera (Retiga; Qimaging, Burnaby, BC, Canada) and analyzed with Northern Eclipse software (Empix Imaging, Mississauga, ON, Canada).

Dendritic arbor and soma size analysis. Dendritic arbor reconstruction and measurements were performed blinded to manipulations. High-resolution images of YFP-labeled RGC dendritic arbors were acquired using a Leica SP1 confocal microscope (Leica Microsystems Inc., Concord, ON, Canada). Scans were taken at 0.48 to $0.65 \mu \mathrm{m}$ intervals along the $\mathrm{z}$ axis ( $\mathrm{x}$ and $\mathrm{y}=1024 \times 1024$ pixels with 4 to 6 images averaged at each focal plane). Reconstruction of the entire RGC dendritic arbor was carried out using the computer-aided filament tracing function of the 3D image analysis software Imaris (Bitplane, South Windsor, CT, USA). The following parameters were measured and analyzed in this study: (i) total dendritic length: the sum of the lengths of all dendrites per neuron, (ii) total dendritic field area: the area within the contour of the arbor created by drawing a line connecting the outermost tips of the dendrites, (iii) branch order. the number of times a dendrite branches, starting with order 1 , which corresponds to the primary branch emerging from the soma, (iv) Scholl analysis: the number of dendrites that cross concentric circles at increasing distances (10 $\mu \mathrm{m}$ interval) from the soma, and (v) soma size: the area within the contour drawn around the RGC soma to outline its shape.

Western blot analysis. Whole fresh retinas were rapidly dissected and homogenized with an electric pestle (Kontes, Vineland, NJ, USA) in ice-cold lysis buffer (20 mM Tris, pH 8.0, $135 \mathrm{mM} \mathrm{NaCl}, 1 \% \mathrm{NP}-40,0.1 \%$ SDS and $10 \%$ glycerol supplemented with protease inhibitors). Protein homogenates were centrifuged at 10000 r.p.m. for $50 \mathrm{~min}$, and the supernatants were removed and resedimented to yield solubilized extracts. Retinal extracts were resolved on SDS-polyacrylamide gels and transferred to nitrocellulose membranes (Bio-Rad Life Science, Mississauga, ON, Canada). Blots were incubated overnight at $4{ }^{\circ} \mathrm{C}$ with each of the following primary antibodies against: REDD2 $(0.5 \mu \mathrm{g} / \mathrm{ml}$; Fitzgerald, Acton, MA, USA), REDD1 $(4 \mu \mathrm{g} / \mathrm{ml}$; Proteintech, Chicago, IL, USA) or $\beta$-actin $(0.5 \mu \mathrm{g} / \mathrm{ml}$; Sigma-Aldrich). Membranes were incubated in anti-rabbit or anti-mouse peroxidaselinked secondary antibodies $(0.5 \mu \mathrm{g} / \mathrm{ml}$; Amersham Biosciences, Baie d'Urfé, QC, Canada). Blots were developed with a chemiluminescence reagent (ECL; Amersham Biosciences) and exposed to X-OMAT imaging film (Eastman Kodak, Rochester, NY, USA). Densitometric analysis was performed using Scion Image software (Scion Corporation, Frederick, MD, USA) on scanned autoradiographic films obtained from a series of three independent western blots each carried out using retinal samples from distinct experimental groups.

siRNA and rapamycin delivery. The siRNA molecules against REDD2 and siCtls were designed and provided by Quark Pharmaceuticals Inc. (Research Division, Ness Ziona, Israel). siRNAs were stabilized by alternating 2'O-methylation ${ }^{69}$ and were synthesized by BioSpring GmbH (Frankfurt, Germany). The following siRNA sequences for REDD2 were tested with similar results (sense strands): 5'-ACGTGAACTTGGAAATTGA-3', 5'-CCCAGAGAATTGCCCAAGA-3' and 5'-TTGGACAGACAGTTCTCCA-3'. siCtls included a non-targeting siCtl: 5'-ACTAAATTACGCGCGATGC-3' (sense strand), and a siCtl-Cy3: 5'-GUGC CAACCUGAUGCAGCU-3' (sense strand). Each siRNA ( $7 \mu \mathrm{g} / \mu \mathrm{l}$; total volume: $2 \mu l$ ) was injected into the vitreous chamber of the left eye using a Hamilton syringe fitted with a 32-gauge glass microneedle. The sclera was exposed and the tip of the needle inserted into the superior ocular hemisphere at a $45^{\circ}$ angle through the sclera and retina into the vitreous space using a posterior approach. This route of administration avoids injury to the iris or lens, which can promote RGC survival. ${ }^{70,71}$ After the injection, surgical glue (Indermill; Tyco Health Care, Mansfield, MA, USA) was immediately used to seal the site of injection. Rapamycin (LC Laboratories, Woburn, MA, USA) diluted in 5\% Tween- 80 and $5 \%$ polyethylene glycol 400 was administered by intraperitoneal injection $(6 \mathrm{mg} / \mathrm{kg})$ at the time of axotomy, and 2 days later, for a total of two treatments. This regimen was selected based on the observation that a single dose of rapamycin $(6 \mathrm{mg} / \mathrm{kg})$ fully inhibits mTOR activity for $60 \mathrm{~h}$ in vivo. ${ }^{72}$

Electrophysiology. Whole-cell recordings were performed on isolated flatmounted retinas of Thy1-YFPH mice as previously described. ${ }^{73}$ Briefly, animals were anesthetized using isoflurane and then killed by decapitation. The killing of the mice and dissections were performed in ambient light, after which retinas were kept in the dark. The eyes were dissected and the retinas were rapidly removed and placed in Ames' solution (Sigma-Aldrich). The vitreous was gently removed and the retinas treated with a collagenase/hyaluronidase mixture $(240$ and $1000 \mathrm{U} / \mathrm{ml}$, respectively; Worthington Biochemical, Lakewood, NJ, USA) at room temperature for 5-10 min. Retinas were mounted with the vitreal side up and superfused with Ames' solution bubbled with $95 \% \mathrm{O}_{2}$ and $5 \% \mathrm{CO}_{2}$ at room temperature. YFPpositive RGCs were visualized with an epifluorescent microscope, captured with an infrared-sensitive CCD camera and displayed on a video monitor. The camera was mounted on an Olympus FluoView FV 1000 confocal microscope equipped with a $\times 40$ water-immersion objective. Whole-cell recordings were performed using a computer-controlled Multiclamp 700A amplifier and a Digidata 1322A digitizer (Axon Instruments, Downingtown, PA, USA). Patch pipettes (resistance 5-7 M $\Omega$ ) were 
pulled from borosilicate glass capillaries $(1.5 \mathrm{~mm}$ OD, $1.12 \mathrm{~mm} \mathrm{ID}$; World Precision Instruments, Sarasota, FL, USA) on a Sutter P-97 puller (Sutter Instruments, Novato, CA, USA). Intracellular solution contained: $140 \mathrm{mM} \mathrm{K-gluconate,} 5 \mathrm{mM}$ $\mathrm{NaCl}, 2 \mathrm{mM} \mathrm{MgCl}$, $10 \mathrm{mM}$ HEPES, $0.5 \mathrm{mM}$ EGTA, Tris $2 \mathrm{mM}$ ATP, Tris $0.4 \mathrm{mM}$ GTP and Alexa Fluor 594 (15-30 $\mu \mathrm{M}$; Molecular Probes) (pH 7.2-7.3, 280-300 mOsmol/ $\mathrm{kg}$ ). During recordings, injection of step current from -250 to $350 \mathrm{pA}$ was carried out to characterize the intrinsic properties of RGCs. An argon laser $(488 \mathrm{~nm})$ was used in the line scan mode to provide a linear stimulus moving at the speed of $4 \mu \mathrm{s}$ per pixel. Data analyses were carried out offline using P-clamp 8 or 9 (Axon Instruments).

Statistical analyses. Data analysis and statistics were performed using the GraphPad Instat software (GraphPad Software Inc., San Diego, CA, USA) by a one-way ANOVA, followed by the Bonferroni or Dunnett's multiple comparison post hoc tests, or by a Student's t-test as indicated in the legends.

\section{Conflict of Interest}

BM, PM, JA, RAM, AK and ADP declare no conflict of interest. EF is Chief Scientific Officer at Quark Pharmaceuticals and owns company's stock options.

Acknowledgements. We thank Drs. TE Kennedy, ES Ruthazer and PP Roux for helpful advice and comments on the manuscript, and Drs. H Kalinski, $\mathrm{H}$ Ashush and I Mett (Quark Pharmaceuticals Inc.) for siRNA design and in vitro activity testing. This study was supported by grants from the Canadian Institutes of Health Research (to ADP), and the Réseau de Recherche en Santé de la Vision (to ADP). BM is the recipient of a fellowship from the Fonds de recherche du Québec-Santé (FRQS) and the Groupe de Recherche sur le Système Nerveux Central (GRSNC). PM is the recipient of a fellowship from the Réseau de recherche en santé buccodentaire et osseuse. ADP is a Chercheur Boursier National FRQS.

\section{Author contributiions}

$\mathrm{BM}, \mathrm{PM}, \mathrm{AK}, \mathrm{RAM}$ and $\mathrm{ADP}$ designed the experiments. EF designed and characterized the siRNAs used in this study. BM, PM and JA performed the experiments. BM, PM, AK and ADP analyzed data and wrote the manuscript.

1. Luo L, O'Leary DDM. Axon retraction and degeneration in development and disease. Ann Rev Neurosci 2005; 28: 127-156.

2. Cheng P-I, Poo M-m. Early events in axon/dendrite polarization. Ann Rev Neurosci 2012; 35: 181-201.

3. Wong RO, Ghosh A. Activity-dependent regulation of dendritic growth and patterning. Nat Rev Neurosci 2002; 3: 803-812.

4. Lin Y-C, Koleske AJ. Mechanisms of synapse and dendrite maintenance and their disruption in psychiatric and neurodegenerative disorders. Ann Rev Neurosci 2010; 33: 349-378.

5. Liu M, Duggan J, Salt TE, Cordeiro MF. Dendritic changes in visual pathways in glaucoma and other neurodegenerative conditions. Exp Eye Res 2011; 92: 244-250.

6. Jaworski J, Spangler S, Seeburg DP, Hoogenraad CC, Sheng M. Control of dendritic arborization by the phosphoinositide-3'-Kinase-Akt-mammalian target of rapamycin pathway. J Neurosci 2005; 25: 11300-11312.

7. Kumar V, Zhang M-X, Swank MW, Kunz J, Wu G-Y. Regulation of dendritic morphogenesis by Ras-PI3K-Akt-mTOR and Ras-MAPK signaling pathways. J Neurosci 2005; 25: 11288-11299.

8. Gao X, Neufeld TP, Pan D. Drosophila PTEN regulates cell growth and proliferation through PI3K-dependent and -independent pathways. Dev Biol 2000; 221: 404-418.

9. Kwon C-H, Luikart BW, Powell CM, Zhou J, Matheny SA, Zhang W et al. Pten regulates neuronal arborization and social interaction in mice. Neuron 2006; 50: 377-388.

10. Hoeffer CA, Klann E. mTOR signaling: at the crossroads of plasticity, memory and disease. Trends Neurosci 2010; 33: 67-75.

11. Li N, Lee B, Liu R-J, Banasr M, Dwyer JM, Iwata M et al. mTOR-dependent synapse formation underlies the rapid antidepressant effects of NMDA antagonists. Science 2010; 329: 959-964.

12. Brugarolas J, Lei K, Hurley RL, Manning BD, Reiling JH, Hafen E et al. Regulation of mTOR function in response to hypoxia by REDD1 and the TSC1/TSC2 tumor suppressor complex. Genes Dev 2004; 18: 2893-2904.

13. Corradetti MN, Inoki K, Guan K-L. The stress-inducted proteins RTP801 and RTP801L are negative regulators of the mammalian target of rapamycin pathway. J Biol Chem 2005; 280: 9769-9772.

14. Sofer A, Lei K, Johannessen CM, Ellisen LW. Regulation of mTOR and cell growth in response to energy stress by REDD1. Mol Cell Biol 2005; 25: 5834-5845.
15. Imen JS, Billiet L, Cuaz-Pérolin C, Michaud N, Rouis M. The regulated in development and DNA damage response 2 (REDD2) gene mediates human monocyte cell death through a reduction in thioredoxin-1 expression. Free Radic Biol Med 2009; 46: 1404-1410.

16. Cuaz-Pérolin C, Furman C, Larigauderie G, Legedz L, Lasselin C, Copin C et al. REDD2 gene is upregulated by modified LDL or hypoxia and mediates human macrophage cell death. Arterioscler Thromb Vasc Biol 2004; 24: 1830-1835.

17. Miyazaki M, Esser KA. REDD2 is enriched in skeletal muscle and inhibits mTOR signaling in response to leucine and stretch. Am J Phys 2009; 296: C583-C592.

18. Feng G, Mellor RH, Bernstein M, Keller-Peck C, Nguyen QT, Wallace M et al. Imaging neuronal subsets in transgenic mice expressing multiple spectral variants of GFP. Neuron 2000; 28: 41-51.

19. Galindo-Romero C, Avilés-Trigueros M, Jiménez-López $M$, Valiente-Soriano FJ, Salinas-Navarro M, Nadal-Nicolás F et al. Axotomy-induced retinal ganglion cell death in adult mice: quantitative and topographic time course analyses. Exp Eye Res 2011; 92: 377-387.

20. Sun W, Li N, He S. Large-scale morphological survey of mouse retinal ganglion cells. J Comp Neurol 2002; 451: 115-126.

21. Coombs J, van der List D, Wang GY, Chalupa LM. Morphological properties of mouse retinal ganglion cells. Neuroscience 2006; 140: 123-136.

22. Jefferies HBJ, Fumagalli S, Dennis PB, Reinhard C, Pearson RB, Thomas G. Rapamycin suppresses 5[prime]TOP mRNA translation through inhibition of p70s6k. EMBO J 1997; 16: 3693-3704.

23. Ikenoue T, Hong S, Inoki K. Monitoring mammalian target of rapamycin (mTOR) activity. Methods Enzymol 2009; 452: 165-180.

24. Cui Q, Yip HK, Zhao RC, So KF, Harvey AR. Intraocular elevation of cyclic AMP potentiates ciliary neurotrophic factor-induced regeneration of adult rat retinal ganglion cell axons. $\mathrm{Mol}$ Cell Neurosci 2003; 22: 49-61.

25. Yin Y, Cui Q, Li Y, Irwin N, Fischer D, Harvey AR et al. Macrophage-derived factors stimulate optic nerve regeneration. J Neurosci 2003; 23: 2284-2293.

26. DeYoung MP, Horak P, Sofer A, Sgroi D, Ellisen LW. Hypoxia regulates TSC1/2-mTOR signaling and tumor suppression through REDD1-mediated 14-3-3 shuttling. Genes Dev 2008; 22: 239-251.

27. Reiling JH, Hafen E. The hypoxia-induced paralogs Scylla and Charybdis inhibit growth by down-regulating S6K activity upstream of TSC in Drosophila. Genes Dev 2004; 18: 2879-2892.

28. Shoshani T, Faerman A, Mett I, Zelin E, Tenne T, Gorodin S et al. Identification of a novel hypoxia-inducible factor 1-responsive gene, RTP801, involved in apoptosis. Mol Cell Biol 2002; 22: 2283-2293.

29. del Olmo-Aguado S, Núñez-Álvarez C, Ji D, Manso AG, Osborne NN. RTP801 immunoreactivity in retinal ganglion cells and its down-regulation in cultured cells protect them from light and cobalt chloride. Brain Res Bull 2013; 98: 132-144.

30. Chung J, Kuo CJ, Crabtree GR, Blenis J. Rapamycin-FKBP specifically blocks growthdependent activation of and signaling by the 70 kd S6 protein kinases. Cell 1992; 69 . 1227-1236.

31. Janssen KT, Mac Nair CE, Dietz JA, Schlamp CL, Nickells RW. Nuclear atrophy of retinal ganglion cells precedes the Bax-dependent stage of apoptosis. Invest Ophthalmol Vis Sci. 2013; 54: 1805-1815.

32. Kwon $\mathrm{C}-\mathrm{H}$, Zhu X, Zhang J, Baker SJ. mTor is required for hypertrophy of Pten-deficient neuronal soma in vivo. Proc Natl Acad Sci USA 2003; 100: 12923-12928.

33. Wong WT, Wong ROL. Rapid dendritic movements during synapse formation and rearrangement. Curr Opin Neurobiol 2000; 10: 118-124.

34. Cline HT. Dendritic arbor development and synaptogenesis. Curr Opin Neurobiol 2001; 11: 118-126.

35. Koleske AJ. Molecular mechanisms of dendrite stability. Nat Rev Neurosci 2013; 14: $536-550$.

36. Almasieh M, Wilson AM, Morquette B, Cueva Vargas JL, Di Polo A. The molecular basis of retinal ganglion cell death in glaucoma. Prog Ret Eye Res 2012; 31: 152-181.

37. Morgan JE, Datta AV, Erichse nJT, Albon J, Boulton ME. Retinal ganglion cell remodelling in experimental glaucoma. Adv Exp Med Biol 2006; 572: 397-402.

38. Shou T, Liu J, Wang W, Zhou Y, Zhao K. Differential dendritic shrinkage of alpha and beta retinal ganglion cells in cats with chronic glaucoma. Invest Ophthalmol Vis Sci 2003; 44: 3005-3010.

39. Weber AJ, Kaufman PL, Hubbard WC. Morphology of single ganglion cells in the glaucomatous primate retina. Invest Ophthalmol Vis Sci 1998; 39: 2304-2320.

40. Li Z-w, Liu S, Weinreb RN, Lindsey JD, Yu M, Liu L et al. Tracking dendritic shrinkage of retinal ganglion cells after acute elevation of intraocular pressure. Invest Ophthalmol Vis Sci 2011; 52: 7205-7212.

41. Williams PA, Howell GR, Barbay JM, Braine CE, Sousa GL, John SWM et al. Retinal ganglion cell dendritic atrophy in DBA/2J glaucoma. PLoS One 2013; 8: e72282.

42. Della Santina L, Inman DM, Lupien CB, Horner PJ, Wong ROL. Differential progression of structural and functional alterations in distinct retinal ganglion cell types in a mouse model of glaucoma. J Neurosci 2013; 33: 17444-17457.

43. Feng L, Zhao Y, Yoshida M, Chen H, Yang JF, Kim TS et al. Sustained ocular hypertension induces dendritic degeneration of mouse retinal ganglion cells that depends on cell type and location. Invest Ophthalmol Vis Sci 2013; 54: 1106-1117. 
44. Pavlidis M, Stupp T, Naskar R, Cengiz C, Thanos S. Retinal ganglion cells resistant to advanced glaucoma: A Postmortem Study of Human Retinas with the Carbocyanine Dye Dil. Invest Ophthalmol Vis Sci 2003; 44: 5196-5205.

45. Nickells RW, Howell GR, Soto I, John SWM. Under pressure: cellular and molecular responses during glaucoma, a common neurodegeneration with axonopathy. Ann Rev Neurosci 2012; 35: 153-179.

46. Kalesnykas G, Oglesby EN, Zack DJ, Cone FE, Steinhart MR, Tian J et al. Retinal ganglion cell morphology after optic nerve crush and experimental glaucoma. Invest Ophthalmol Vis Sci 2012; 53: 3847-3857.

47. Leung CK-s, Weinreb RN, Li ZW, Liu S, Lindsey JD, Choi N et al. Long-term in vivo imaging and measurement of dendritic shrinkage of retinal ganglion cells. Invest Ophthalmol Vis Sci 2011; 52: 1539-1547.

48. Lin B, Wang SW, Masland RH. Retinal ganglion cell type, size, and spacing can be specified independent of homotypic dendritic contacts. Neuron 2004; 43: 475-485.

49. Kim I-J, Zhang Y, Yamagata M, Meister M, Sanes JR. Molecular identification of a retinal cell type that responds to upward motion. Nature 2008; 452: 478-482.

50. Weber AJ, Harman CD. BDNF preserves the dendritic morphology of $\alpha$ and $\beta$ ganglion cells in the cat retina after optic nerve injury. Invest Ophthalmol Vis Sci 2008; 49: 2456-2463.

51. Ortells MC, Morancho B, Drews-Elger K, Viollet B, Laderoute KR, López-Rodríguez C et al. Transcriptional regulation of gene expression during osmotic stress responses by the mammalian target of rapamycin. Nucleic Acids Res 2012; 40: 4368-4384.

52. Ergorul C, Ray A, Huang W, Wang D, Ben Y, Cantuti-Castelvetri I et al. Hypoxia inducible factor-1 $\alpha(\mathrm{HIF}-1 \alpha)$ and some HIF-1 target genes are elevated in experimental glaucoma J Mol Neurosci 2010; 42: 183-191.

53. Kanamori A, Catrinescu M-M, Kanamori N, Mears KA, Beaubien R, Levin LA. Superoxide is an associated signal for apoptosis in axonal injury. Brain 2010; 133: 2612-2625.

54. Park KK, Liu K, Hu Y, Smith PD, Wang C, Cai B et al. Promoting axon regeneration in the adult CNS by modulation of the PTEN/mTOR pathway. Science 2008; 322: 963-966.

55. Park KK, Liu K, Hu Y, Kanter JL, He Z. PTEN/mTOR and axon regeneration. Exp Neurol 2010; 223: 45-50.

56. Morgan-Warren PJ, Berry M, Ahmed Z, Scott RAH, Logan A. Exploiting mTOR signaling: a novel translatable treatment strategy for traumatic optic neuropathy? Invest Ophthalmol Vis Sci 2013; 54: 6903-6916.

57. Kurimoto T, Yin Y, Omura K, Gilbert H-y, Kim D, Cen L-P et al. Long-distance axon regeneration in the mature optic nerve: contributions of oncomodulin, CAMP, and pten gene deletion. J Neurosci 2010; 30: 15654-15663.

58. Leibinger M, Andreadaki A, Fischer D. Role of mTOR in neuroprotection and axon regeneration after inflammatory stimulation. Neurobiol Dis. 2012; 46: 314-324.

59. Swiech L, Blazejczyk M, Urbanska M, Pietruszka P, Dortland BR, Malik AR et al. CLIP-170 and IQGAP1 cooperatively regulate dendrite morphology. J Neurosci 2011; 31 4555-4568.

60. Malik AR, Urbanska M, Macias M, Skalecka A, Jaworski J. Beyond control of protein translation: What we have learned about the non-canonical regulation and function of mammalian target of rapamycin (mTOR). Biochim Biophys Acta 2013; 1834: 1434-1448.

61. Ward NJ, Ho KW, Lambert WS, Weitlauf C, Calkins DJ. Absence of transient recepto potential vanilloid-1 accelerates stress-induced axonopathy in the optic projection. J Neurosci 2014; 34: 3161-3170.
62. Raab-Graham KF, Haddick PCG, Jan YN, Jan LY. Activity- and mTOR-dependent suppression of Kv1.1 channel mRNA translation in dendrites. Science 2006; 314: 144-148.

63. Cudmore RH, Fronzaroli-Molinieres L, Giraud P, Debanne D. Spike-time precision and network synchrony are controlled by the homeostatic regulation of the D-type potassium current. J Neurosci 2010; 30: 12885-12895.

64. Metz AE, Spruston N, Martina M. Dendritic D-type potassium currents inhibit the spike afterdepolarization in rat hippocampal CA1 pyramidal neurons. J Physiol 2007; 581: 175-187.

65. Bateup Helen S, Johnson Caroline A, Denefrio Cassandra L, Saulnier Jessica L, Kornacker K, Sabatini Bernardo L. Excitatory/inhibitory synaptic imbalance leads to hippocampal hyperexcitability in mouse models of tuberous sclerosis. Neuron 2013; 78: 510-522.

66. Lebrun-Julien F, Morquette B, Douillette A, Saragovi HU, Di Polo A. Inhibition of p75NTR in glia potentiates TrkA-mediated survival of injured retinal ganglion cells. Mol Cell Neurosci 2009; 40: 410-420.

67. Lebrun-Julien F, Duplan L, Pernet V, Osswald IK, Sapieha P, Bourgeois P et al. Excitotoxic death of retinal neurons in vivo occurs via a non-cell-autonomous mechanism. $J$ Neurosci 2009; 29: 5536-5545

68. Nadal-Nicolás FM, Jiménez-López M, Sobrado-Calvo P, Nieto-López L, Cánovas-Martínez I, Salinas-Navarro $\mathrm{M}$ et al. Brn3a as a marker of retinal ganglion cells: qualitative and quantitative time course studies in naïve and optic nerve-injured retinas. Invest Ophthalmol Vis Sci 2009; 50: 3860-3868.

69. Czauderna F, Fechtner M, Dames S, Aygun H, Klippel A, Pronk GJ et al. Structural variations and stabilising modifications of synthetic siRNAs in mammalian cells. Nucleic Acids Res 2003; 31: 2705-2716.

70. Leon S, Yin Y, Nguyen J, Irwin N, Benowitz LI. Lens injury stimulates axon regeneration in the mature rat optic nerve. J Neurosci 2000; 20: 4615-4626.

71. Mansour-Robaey S, Clarke DB, Wang Y-C, Bray GM, Aguayo AJ. Effects of ocular injury and administration of brain-derived neurotrophic factor on survival and regrowth of axotomized retinal ganglion cells. Proc Natl Acad Sci USA 1994; 91: 1632-1636.

72. Meikle L, Pollizzi K, Egnor A, Kramvis I, Lane H, Sahin M et al. Response of a neuronal model of tuberous sclerosis to mammalian target of rapamycin (mTOR) inhibitors: effects on mTORC1 and Akt signaling lead to improved survival and function. $J$ Neurosci 2008; 28: $5422-5432$

73. Schmidt TM, Kofuji P. An isolated retinal preparation to record light response from genetically labeled retinal ganglion cells. J Vis Exp 2011; 47: 2367.

(c) (3) (2) This work is licensed under a Creative Commons Attribution-NonCommercial-ShareAlike 3.0 Unported License. The images or other third party material in this article are included in the article's Creative Commons license, unless indicated otherwise in the credit line; if the material is not included under the Creative Commons license, users will need to obtain permission from the license holder to reproduce the material. To view a copy of this license, visit http://creativecommons.org/licenses/by-nc-sa/3.0/ 